\title{
Muscarinic Receptors Modulate Dendrodendritic Inhibitory Synapses to Sculpt Glomerular Output
}

\author{
DShaolin Liu, ${ }^{1}$ Zuoyi Shao, ${ }^{1}$ Adam Puche, ${ }^{1}$ Matt Wachowiak, ${ }^{2}$ Markus Rothermel, ${ }^{2}$ and Michael T. Shipley ${ }^{1}$ \\ ${ }^{1}$ Department of Anatomy \& Neurobiology and Program in Neuroscience, University of Maryland School of Medicine, Baltimore, Maryland 21201, and \\ ${ }^{2}$ Department of Neurobiology and Anatomy and Brain Institute, University of Utah, Salt Lake City, Utah 84112
}

Cholinergic [acetylcholine (ACh)] axons from the basal forebrain innervate olfactory bulb glomeruli, the initial site of synaptic integration in the olfactory system. Both nicotinic acetylcholine receptors (nAChRs) and muscarinic acetylcholine receptors (mAChRs) are expressed in glomeruli. The activation of nAChRs directly excites both mitral/tufted cells (MTCs) and external tufted cells (ETCs), the two major excitatory neurons that transmit glomerular output. The functional roles of mAChRs in glomerular circuits are unknown. We show that the restricted glomerular application of ACh causes rapid, brief nAChR-mediated excitation of both MTCs and ETCs in the mouse olfactory bulb. This excitation is followed by mAChR-mediated inhibition, which is blocked by $\mathrm{GABA}_{\mathrm{A}}$ receptor antagonists, indicating the engagement of periglomerular cells (PGCs) and/or short axon cells (SACs), the two major glomerular inhibitory neurons. Indeed, selective activation of glomerular mAChRs, with ionotropic GluRs and nAChRs blocked, increased IPSCs in MTCs and ETCs, indicating that $\mathrm{mAChRs}$ recruit glomerular inhibitory circuits. Selective activation of glomerular mAChRs in the presence of tetrodotoxin increased IPSCs in all glomerular neurons, indicating action potential-independent enhancement of GABA release from PGC and/or SAC dendrodendritic synapses. mAChR-mediated enhancement of GABA release also presynaptically suppressed the first synapse of the olfactory system via $\mathrm{GABA}_{\mathrm{B}}$ receptors on sensory terminals. Together, these results indicate that cholinergic modulation of glomerular circuits is biphasic, involving an initial excitation of MTC/ETCs mediated by nAChRs followed by inhibition mediated directly by mAChRs on PGCs/SACs. This may phasically enhance the sensitivity of glomerular outputs to odorants, an action that is consistent with recent in vivo findings.

Key words: cholinergic modulation; dendrodendritic synapses; glomerular circuits; glomerular output; inhibitory interneurons; olfactory bulb

\section{Introduction}

Basal forebrain cholinergic neurons target many brain regions and play roles in sensory processing, attention, reward, and learning/memory (Zaborszky et al., 2012; Thiele, 2013). The olfactory bulb $(\mathrm{OB})$ receives acetylcholine $(\mathrm{ACh})$ input from the diagonal band of Broca (DB) in the basal forebrain (Price and Powell, 1970; Wenk et al., 1977; de Olmos et al., 1978; Macrides et al., 1981; Zaborszky et al., 1986), and ACh modulation has been implicated in odor discrimination and olfactory memory (Roman et al., 1993; Ravel et al., 1994; Doty et al., 1999; De Rosa et al., 2001; Linster et al., 2001; Fletcher and Wilson, 2002; Mandairon et al., 2006; Chaudhury et al., 2009; Fletcher and Chen, 2010).

\footnotetext{
Received Dec. 5, 2014; revised Feb. 3, 2015; accepted March 3, 2015

Author contributions: S.L., Z.S., A.P., M.R., and M.T.S. designed research; S.L. and Z.S. performed research; S.L. and Z.S. analyzed data; S.L., M.W., and M.T.S. wrote the paper.

This research was supported by National Institutes of Health Grants DC010915 and DC005676.

The authors declare no competing financial interests.

Correspondence should be addressed to either Shaolin Liu or Michael T. Shipley, Department of Anatomy \&

Neurobiology and Program in Neuroscience, University of Maryland School of Medicine, 20 Penn Street, Baltimore, MD 21201. E-mail: sliu003@umaryland.edu or mshipley@umaryland.edu.

M. Rothermel's present address: Department of Chemosensation, Institute for Biology II, RWTH, Aachen University, 2 Sammelbau Biologie Worringerweg 3, D-52074 Aachen, Germany.

DOI:10.1523/JNEUROSCI.4953-14.2015

Copyright $\odot 2015$ the authors $\quad 0270-6474 / 15 / 355680-13 \$ 15.00 / 0$
}

However, the $\mathrm{OB}$ neurons, circuits, and cholinergic receptors underlying these actions remain unclear.

Findings from in vivo studies are inconsistent. For example, electrical stimulation of DB increases (Nickell and Shipley, 1988b; Zhan et al., 2013) or decreases (Inokuchi et al., 1987; Kunze et al., 1991) the activities of mitral/tufted cells (MTCs) by regulating the excitability of GABAergic granule cells (GCs). Local application of cholinergic agonists in the $\mathrm{OB}$ in vivo also excites MTCs via direct inhibition of GABAergic GCs (disinhibition; Elaagouby et al., 1991). Discrepancies among studies using electrical stimulation may be due to nonselective activation of DB neurons, which in addition to cholinergic neurons, contain GABAergic and glutamatergic neurons (Zaborszky et al., 1986, 2012; Nunez-Parra et al., 2013). Recent studies using optogenetics to selectively activate cholinergic inputs to the OB also reported discrepant findings. Optogenetic activation of cholinergic neurons in the DB inhibits MTCs as well as other cell types in the OB (Ma and Luo, 2012), whereas optogenetic activation of cholinergic axons in the OB excites MTCs (Rothermel et al., 2014). This may be because optogenetic stimulation of the DB (Ma and Luo, 2012) activates not only the cholinergic projection to the $\mathrm{OB}$ but also cholinergic projections to other brain regions, including anterior olfactory nucleus, and piriform and entorhinal cortices, which interconnect with the OB (Shipley and Adamek, 1984; 
Woolf et al., 1984; Zaborszky et al., 1986, 2012; Boyd et al., 2012; Markopoulos et al., 2012).

To help reconcile disparate interpretations from in vivo findings, it is important to better understand the actions of ACh on glomerular cells and circuits. To this end, we systematically examined ACh actions on genetically and anatomically identified glomerular neurons and circuits in OB slices. Our results demonstrate that $\mathrm{ACh}$ activates both fast-acting nicotinic ACh receptors (nAChRs) and slower-onset muscarinic ACh receptors (mAChRs) on glomerular interneurons to regulate the excitability of MTCs, the principal output neurons of the OB.

\section{Materials and Methods}

Animals. Wild-type male mice $(\mathrm{C} 57 \mathrm{BL} / 6 \mathrm{~J})$ were obtained from Charles River Laboratories. Choline acetyltransferase (ChAT)-Cre (ChAT-IRES-Cre; stock \#006410) and ChAT-ChR-EYFP mice [B6.Cg$\mathrm{Tg}($ Chat-COP4*H134R/EYFP,Slc17A3)6Gfng; stock \#014546, Jackson Laboratories] were used to selectively label and optogenetically activate cholinergic neurons. The ChAT-Cre colony was maintained by breeding between male and female homozygous mice while the ChAT-ChR2 colony was maintained by breeding between male hemizygous ChAT-ChR2 mice and female C57BL/6J mice. The glutamate decarboxylase (GAD)65GFP mice used for selective recording from GABAergic periglomerular cells (PGCs; Shao et al., 2009; Kiyokage et al., 2010) were obtained courtesy of Dr. Gabor Szabo (University of Debrecen, Debrecen, Hungary) (López-Bendito et al., 2004), from the line GAD65_3e/gfp5.5 \#30 on a genetic background of C57BL6 with backcross to B6CBAF1/J wild-type mice, yielding mice heterozygous for the transgene. Tyrosine hydroxylase (TH)-GFP mice used for selective recording from dopaminergic/ GABAergic short axon cells (SACs; Kiyokage et al., 2010; Liu et al., 2013) were courtesy of Dr. Kazuto Kobayashi (Japan Science and Technology Agency, Kawaguchi, Japan) (Matsushita et al., 2002), generated using a $9.0 \mathrm{~kb} 5^{\prime}$-flanking region of the TH gene on a genetic background of $\mathrm{C} 57 \mathrm{BL} / 6 \mathrm{~J} \times \mathrm{DBA} / 2 \mathrm{~J}$ backcrossed to $\mathrm{C} 57 \mathrm{BL} / 6 \mathrm{~J}$, yielding mice that are heterozygous for the transgene. All animals were maintained with a standard $12 \mathrm{~h}$ light/dark cycle, and were given food and water ad libitum. All experimental procedures were performed in accordance with protocols submitted to and approved by the University of Maryland Institutional Animal Care and Use Committee.

Virus-mediated channelrhodopsin 2 expression. Channelrhodopsin 2 (ChR2) expression in cholinergic neurons in the DB was achieved via recombinant viral vector AAV2/5.EF1a.DIO.hChR2(H134R)-EYFP. WPRE.hGH (University of Pennsylvania Viral Vector Core; reported viral titer, $6.7 \times 10^{11}$ to $\left.2.0 \times 10^{13}\right)$ injected at a rate of $0.1 \mu \mathrm{l} / \mathrm{min}$ for 10 min with the following stereotaxic coordinates (in $\mathrm{mm}$ ): 0.74 from Bregma, 0.65 from midline, 4.8 deep from pia at postnatal age of $4 \sim 5$ weeks. After 5-7 weeks for ChR2 enhanced yellow fluorescent protein expression, acute $\mathrm{OB}$ slices were prepared for experiments.

Slice preparation. Acute OB slices from 10- to 12-week-old male mice were prepared as previously described (Liu and Shipley, 2008b). Briefly, horizontal slices $(350 \mu \mathrm{m})$ were cut with a VT1200s Vibratome (Leica) in ice-cold and oxygenated $\left(95 \% \mathrm{O}_{2}-5 \% \mathrm{CO}_{2}\right)$ sucrose-based artificial CSF (ACSF) containing the following (in $\mathrm{mm}$ ): 204.5 sucrose, $3 \mathrm{KCl}, 1.2$ $\mathrm{NaH}_{2} \mathrm{PO}_{4}, 2.6 \mathrm{MgSO}_{4}, 0.5 \mathrm{CaCl}_{2}, 26 \mathrm{NaHCO}_{3}$, and 10 glucose. After 30 min of incubation in normal ACSF at $30^{\circ} \mathrm{C}$, slices were then transferred to ACSF at room temperature until they were used for recordings. Normal ACSF was continuously bubbled with $95 \% \mathrm{O}_{2}-5 \% \mathrm{CO}_{2}$ and had the following composition (in $\mathrm{mM}$ ): $124 \mathrm{NaCl}, 3 \mathrm{KCl}, 1.2 \mathrm{NaH}_{2} \mathrm{PO}_{4}, 1.3$ $\mathrm{MgSO}_{4}, 1.3 \mathrm{CaCl}_{2}, 26 \mathrm{NaHCO}_{3}$, and 10 glucose. During experiments, slices were perfused at $3 \mathrm{ml} / \mathrm{min}$ with ACSF equilibrated with $95 \%$ $\mathrm{O}_{2}-5 \% \mathrm{CO}_{2}$ and warmed to $30^{\circ} \mathrm{C}$.

Electrophysiology. Whole-cell patch-clamp recordings were made from OB visualized using a BX50WI (Olympus) fixed-stage upright microscope equipped with near-infrared differential interference contrast (DIC) optics. SACs and PGCs were identified by their expression of TH-EGFP or GAD65-EGFP, respectively.

External tufted cells (ETCs) were initially reported in Golgi anatomy studies (Ramón y Cajal, 1911; Pinching and Powell, 1971a,c; Macrides and Schneider, 1982). Recently, ETCs were more rigorously characterized by correlating their morphological and electrophysiological properties (Hayar et al., 2004b; Antal et al., 2006). Based on these studies, we define ETCs by the following three criteria: (1) spontaneous intrinsic burst firing that persists even when fast synaptic transmitter receptors are blocked (Hayar et al., 2004b; Liu and Shipley, 2008b); (2) a "pearshaped" cell body located in the deep half of the glomerular layer when viewed in near-IR DIC optics; and (3) an apical dendrite with extensively ramified tuft confined to the glomerulus and the absence of lateral dendrites in the external plexiform layer (EPL). A second type of tufted cell ( $\sim 30 \%$ of the population), has lateral dendrites in the EPL and requires depolarizing current to exhibit bursting (Antal et al., 2006). We recognize cells with these features (Hayar et al., 2004b) but refer to them as "superficial tufted cells" to avoid confusion.

To visualize the recorded MTCs and their apical dendrite tufts in the glomerular layer, Lucifer yellow $(0.01 \%, \mathrm{w} / \mathrm{v})$ was included in the internal solution. Current or voltage signals were recorded with a MultiClamp 700B Amplifier (Molecular Devices), and low-pass filtered at $4 \mathrm{kHz}$ and sampled at $10 \mathrm{kHz}$ with a DIGIDATA $1322 \mathrm{~A} 16$ bit analog-to-digital converter (Molecular Devices) using Clampex version 9.2 (Molecular Devices). Patch recording electrodes were pulled from standard-wall glass capillary tubes without filament (Sutter Instrument). Patch pipettes (4-7 M $\Omega$ ) for whole-cell recording contained the following (in mM): 115 K-gluconate, 5.0 EGTA, $0.63 \mathrm{CaCl}_{2}, 5.5 \mathrm{Mg}-\mathrm{Cl}_{2}, 10 \mathrm{HEPES}, 3 \mathrm{Na}_{2}$-ATP, $0.3 \mathrm{Na}_{3}$-GTP, and 14 Tris-phosphocreatine, $\mathrm{pH} 7.3$ and 285-295 mOsm. To optimize the recording of IPSCs, cells were voltage clamped at $0 \mathrm{mV}$ with an internal solution containing the following (in $\mathrm{mM}$ ): 133 $\mathrm{CsCH}_{3} \mathrm{O}_{3} \mathrm{~S}, 3$ EGTA, $0.4 \mathrm{CaCl}_{2}, 5$ QX-314, $4 \mathrm{MgCl}_{2}, 10$ HEPES, $3 \mathrm{Na}_{2}$ ATP, and $0.3 \mathrm{Na}_{3}$-GTP, pH 7.3 and 285-295 mOsm. When the $\mathrm{GABA}_{\mathrm{A}}$ receptor $\left(\mathrm{GABA}_{\mathrm{A}} \mathrm{R}\right)$ blocker gabazine $(\mathrm{GBZ})$ was bath applied, 2,3dihydroxy-6-nitro-7-sulfonyl-benzo[f] quinoxaline (NBQX; $10 \mu \mathrm{M})$ and aminophosphonovalerate (APV; $50 \mu \mathrm{M}$ ) were preapplied to prevent epileptic activity (Isokawa, 1996).

Electrical and optical stimulation. Electrical stimulation of olfactory nerve axons $(10-50 \mu \mathrm{A})$ was delivered by bipolar glass electrodes made from theta borosilicate tubes (Sutter Instrument) that were visually positioned just outside a glomerulus. Isolated, constant current pulses (100 $\mu \mathrm{s})$ were triggered by a PG4000A Digital Stimulator (Cygnus Technologies). Optical stimuli $(0.5-12 \mathrm{~mW})$ were delivered from a $25 \mu \mathrm{m}$ multimode optical fiber $\left(0.1\right.$ numerical aperture, $\sim 7^{\circ}$ beam spread; ThorLabs) coupled to a $150 \mathrm{~mW}, 473 \mathrm{~nm}$, diode-pumped, solid-state laser (LWBL473083272) and gated with a Uniblitz shutter. Optical power delivered at the fiber tip was calibrated with a PM20A Power Meter (ThorLabs). The onset and duration of optical stimulation was measured during every experiment by splitting $1 \%$ of the laser beam out to a highspeed (30 ns rise time) silicon photosensor (model 818-BB, Newport) and was recorded by the same MultiClamp 700B amplifier as the patch electrode.

Data analysis. Amplitudes and frequencies of spontaneous IPSCs (sIPSCs) or miniature IPSCs (mIPSCs) were measured with Mini Analysis (Synaptosoft). Drug effects on sIPSCs and mIPSCs were determined by measuring these parameters from traces of 1 min duration taken immediately before or $1 \mathrm{~min}$ (micropuffing) or $2 \mathrm{~min}$ (bath application) after drug application in each condition for each cell. Other data were measured and analyzed with Clampfit version 9.2 (Molecular Devices), SigmaPlot version 9.0 (Systat Software), NeuroExplorer (Nex Technologies), and Origin version 8.5 (Origin Lab). The statistical significance of population responses was calculated by using a paired $t$ test (Figs. $1 \mathrm{H}, 2 \mathrm{~B}$; also see Figs. $4 D, F, 6 A, B, 7 D, F)$ or one-way or repeated-measures ANOVA with Bonferroni post hoc comparisons (Fig. $1 E, K$; also see Fig. $5 B, C, E, F)$. The significance of individual cell firing frequency changes was assessed with the Kolmogorov-Smirnov test (Fig. 2).

Drug delivery and chemicals. Drugs were either bath applied or micropuffed ( $1 \mathrm{~mm} \mathrm{ACh}$ ) to target glomeruli by 30 psi pneumatic pressure via a picospritzer (General Valve) for $1 \mathrm{~s}$, as described in previous studies (D'Souza and Vijayaraghavan, 2012; Shao et al., 2012; D'Souza et al., 2013). Injection pipettes ( $6 \mu \mathrm{m}$ tip opening) were made from thick-wall borosilicate glass without filament. These parameters were calibrated to deliver an injection volume of $\sim 20 \mathrm{nl}$ and were previously shown to 
A

B
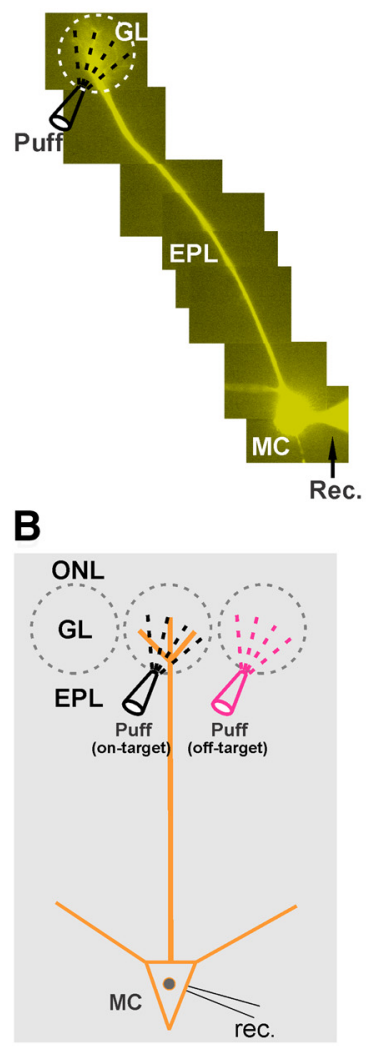

C

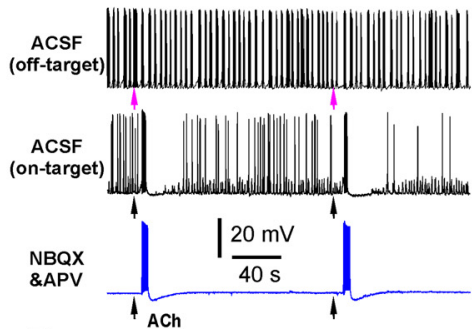

D

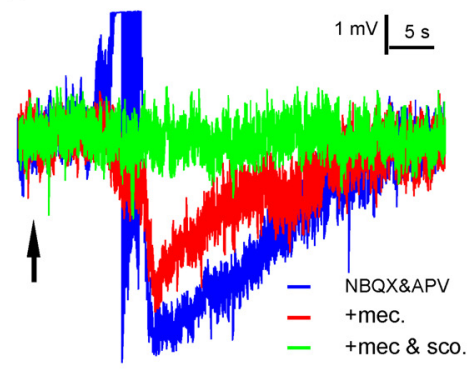

E

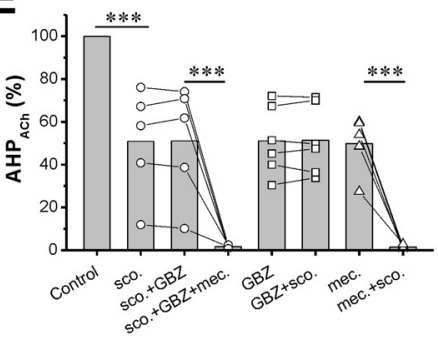

F

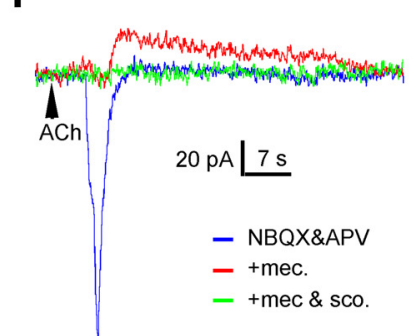

G

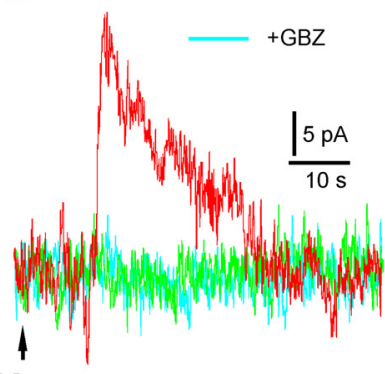

H

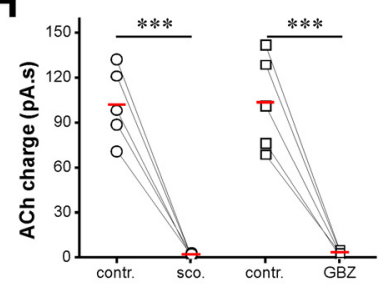

I

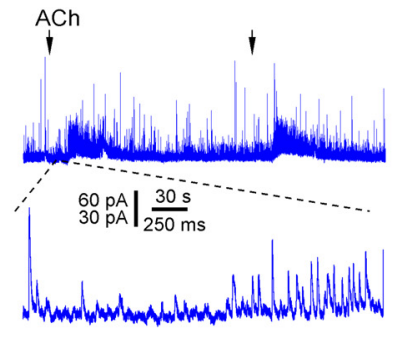

J
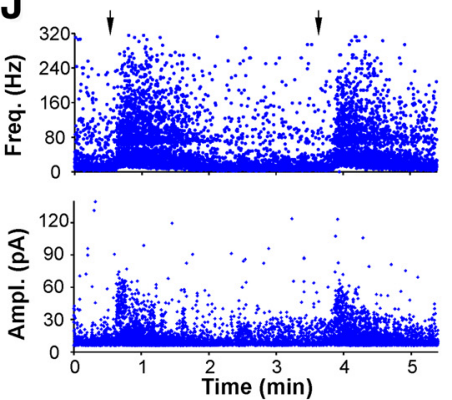

K

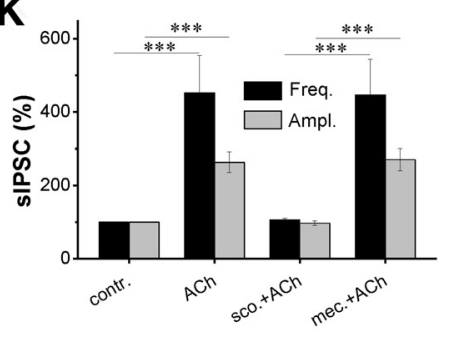

Figure 1. Cholinergic modulation of the glomerular circuit shapes OB output. $A$, Epifluorescent image showing a Lucifer yellow labeled MC. GL, Glomerular layer; MC, mitral cell; puff, puffing pipette; rec., recording electrode. $B$, Schematic of experimental setup showing the pipette for puffing ACh to the off-target (magenta) or on-target (black) glomerulus receiving the apical dendrite of the recorded MTC. ONL, Olfactory nerve layer. C, Current-clamp recording showing MTC responses to (arrows, 1 mm, $1 \mathrm{~s}$ ) the "off-target" (top trace) or "on-target" (middle and bottom traces) micropuffing ACh, as illustrated in B before ACSF, and after NBQX (10 $\mu \mathrm{m})$ and APV (50 $\mu \mathrm{m})$. Note: off-target puffing of ACh showed no effect, while on-target puffing of ACh elicited a brief enhancement of firing followed by hyperpolarization and firing termination; and this effect was not affected by NBQX and APV. D, Typical current-clamp recording traces from one MTC showing that the $\mathrm{nAChR}$ blocker mecamylamine (mec.; $10 \mu \mathrm{m}$, red) abolished the ACh-evoked firing and reduced the following hyperpolarization in the presence of NBQX and APV (blue); the residual hyperpolarization is eliminated by the addition of scopolamine (sco.; $10 \mu \mathrm{M}$, green). $\boldsymbol{E}$, Quantification data from five MTCs showing the following: (1) that the ACh-induced hyperpolarization in the presence of NBQX and APV (Control) is partially reduced by scopolamine, GBZ (10 $\mu \mathrm{M})$, or mecamylamine, and was completely eliminated by scopolamine plus mecamylamine; and (2) that the residual hyperpolarization in the presence of scopolamine or GBZ is not affected by the combination of scopolamine and GBZ. $F$, Voltage-clamp recording traces from the same MTC showing that glomerular micropuffing of ACh to the target glomeruli produces an inward current in the MTC held at $-60 \mathrm{mV}$ in the presence of NBQX and APV (blue). The addition of mecamylamine (10 $\mu \mathrm{m}$ ) in the bath blocks this inward current but reveals an outward current (red). This outward current is abolished by the further addition of scopolamine (10 $\mu \mathrm{M}$ ). $G$, Voltage-clamp recording traces showing that glomerular micropuffed ACh-induced outward current in the presence of NBQX, APV, and mecamylamine (red) is blocked by the further addition of either scopolamine (green) or GBZ (cyan). $\boldsymbol{H}$, Quantification data from five MTCs showing that the ACh-induced outward current shown in $E$ is abolished by either scopolamine or GBZ. I, Typical voltage-clamp recordings showing that glomerular micropuffing of ACh (arrows) reproducibly enhances spontaneous IPSCs in MTCs (top trace). The bottom trace is a blow-up from the top trace showing the initial changes in sIPSCs in response to ACh application. J, Scatter plots showing that both the frequency (top graph) and amplitude (bottom graph) of sIPSCs in MTCs are increased by glomerular micropuffed ACh. $\boldsymbol{K}$, Quantification data from five MTCs showing that the enhancement of both frequency (top graph) and amplitude (bottom graph) of sIPSCs by glomerular-applied ACh is eliminated by scopolamine (10 $\mu \mathrm{m}$ ), but not by mecamylamine $(10 \mu \mathrm{m})$. One-way ANOVA was performed in $\boldsymbol{E}$, between control and sco. Ampl., Amplitude; Freq., frequency. Groups in $\boldsymbol{K}$; repeated-measures ANOVA was performed in comparison among sco., sco. $+\mathrm{GBZ}$, and sco. $+\mathrm{GBZ}+$ mec. groups in $\boldsymbol{E}$. Paired $t$ tests were performed among GBZ and GBZ $+\mathrm{sco}$., mec., and mec. $+\mathrm{sco}$. groups in $\boldsymbol{E}$, as well as in $\boldsymbol{H}$. ${ }^{* * *} p<0.001$.

block inhibition restricted to a single glomerulus (Shao et al., 2012). The concentration and duration of the ACh puffing application were based on our previous studies (D'Souza and Vijayaraghavan, 2012; Shao et al., 2012; D'Souza et al., 2013) with the same micropipette drug application approach (volume, time, and diffusion kinetic calculation yield a puff source concentration that needs to be $5-10$ times the total bath delivery to have the same effective concentrations at the target).

APV (50 $\mu \mathrm{M})$, NBQX disodium salt (10 $\mu \mathrm{M})$, GBZ (SR95531, $10 \mu \mathrm{M})$, tetrodotoxin (TTX) citrate $(1 \mu \mathrm{M})$, and N,2,3,3-Tetramethylbicyclo[2.2.1]heptan-2amine hydrochloride (mecamylamine hydrochloride, $10 \mu \mathrm{M}$ ) were purchased from Tocris Cookson. ACh chloride (1 mM for puffing and $200 \mu \mathrm{M}$ for bath application; D'Souza and Vijayaraghavan, 2012; Shao et al., 2012; D'Souza et al., 2013), 2-hydroxyethyl)trimethylammonium chloride carbamate [carbachol (CCh); $20 \mu \mathrm{M}$ ], (-)-scopolamine hydrochloride (10 $\mu \mathrm{M})$, and all other chemicals were purchased from Sigma-Aldrich. All drugs were dissolved in distilled water as a stock solution and diluted 1000 times with ACSF to the final concentration indicated above.

\section{Results}

\section{Cholinergic modulation of $\mathrm{OB}$ output via the glomerular} circuit

To assess the impact of cholinergic modulation of glomeruli on $\mathrm{OB}$ output neurons, spontaneous firing activity of MTCs was recorded in current clamp. Lucifer yellow was included in the patch pipette solution to visualize apical dendrites of the recorded MTCs (Fig. 1A) so that ACh (1 mM, $1 \mathrm{~s}$ ) could be selectively micropuffed into the glomerulus associated with the recorded MTCs, as previously performed (Shao et al., 2012; Fig. $1 B)$. To ensure that the actions of micropuffed ACh were re- 
A

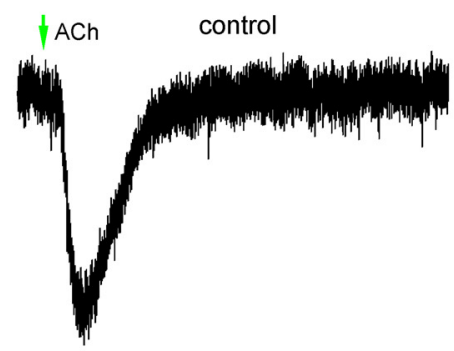

ACSF

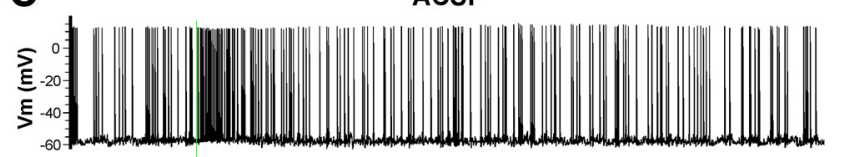

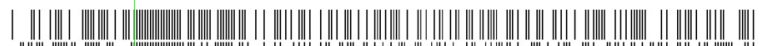

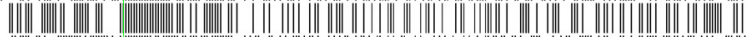

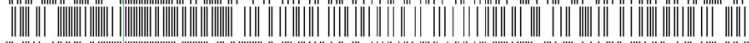

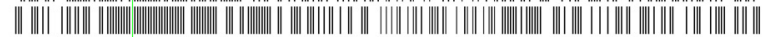
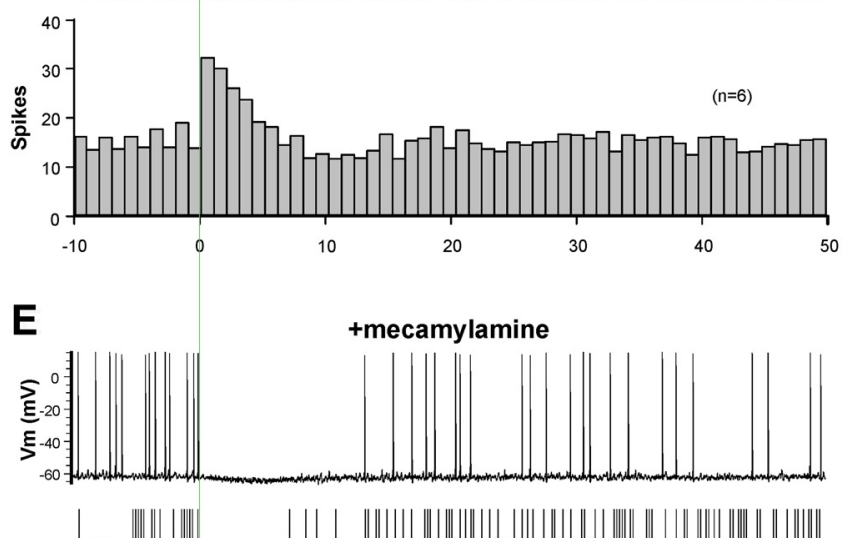

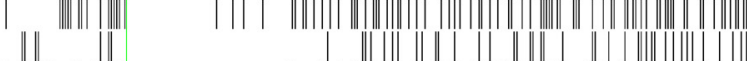

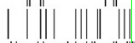

\|\|||$|\||\|\mid\|$

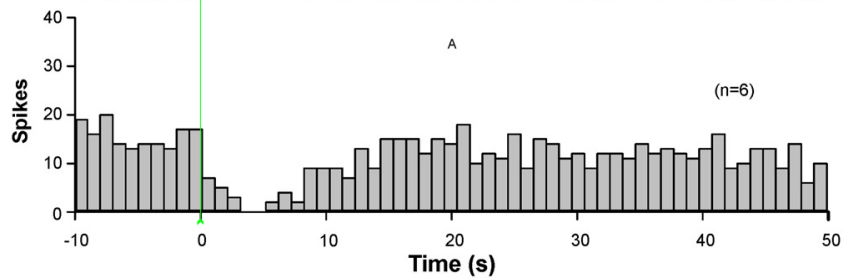

D
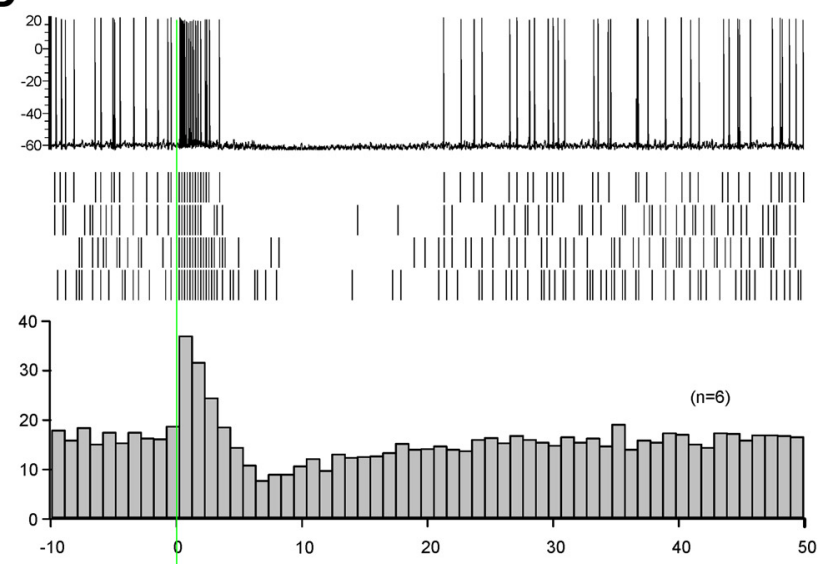

$\mathbf{F}$

+mecamylamine\&scopolamine

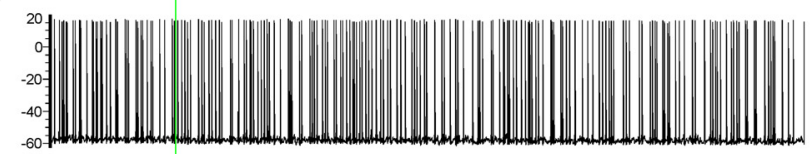

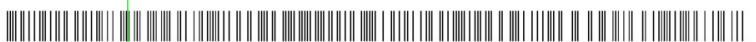

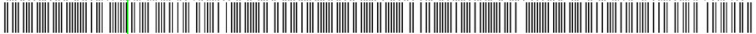

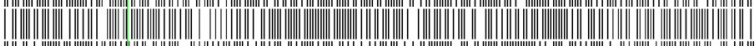

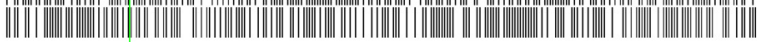

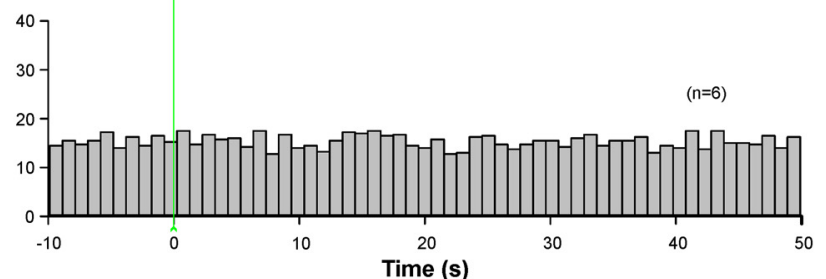

Figure 2. Glomerular ACh produces a direct and nAChR-mediated excitation followed by an mAChR-mediated inhibition in ETCs. A, Voltage-clamp traces showing that micropuffing of ACh (arrows, $1 \mathrm{~mm}, 1 \mathrm{~s}$ ) to the glomeruli receiving apical dendrites of the recorded ETC held at $-60 \mathrm{mV}$ produces an inward current (left, black) in the presence of NBQX (10 $\mu \mathrm{M}$ ), APV (50 $\mu \mathrm{M}$ ), and GBZ $(10 \mu \mathrm{M})$. This ACh-induced inward current is abolished by bath-applied mecamylamine (10 $\mu \mathrm{M}$, right, red). B, Quantification data from five ETCs showing that the glomerular applied ACh-induced inward current is abolished by mecamylamine. C, Top, Current-clamp trace showing that glomerular micropuffing of ACh $(1 \mathrm{~mm}, 1 \mathrm{~s}$, red line) induces a brief firing enhancement in an ETC from the OB slice perfused with ACSF. Middle, Raster graph showing the ACh effect on ETC firing in four repeated traces from the same cell. Bottom, Averaged histogram from six ETCs showing the ACh-induced enhancement of ETC firing (bin size, 1 s). D, Data collected from the same cell shown in ( showing that bath-applied NBQX (10 $\mu \mathrm{M}$ ) and APV (50 $\mu \mathrm{m}$ ) do not alter the ACh-induced brief enhancement of ETC firing but reveal a following spiking termination/inhibition. $\boldsymbol{E}$, Data collected from the same cell shown in $\boldsymbol{C}$ and $\boldsymbol{D}$ showing that the addition of mecamylamine (10 $\mu \mathrm{m})$ abolishes the ACh-induced firing enhancement, but leaves the inhibition intact. $\boldsymbol{F}$, Data collected from the same cell shown in $\boldsymbol{C}, \boldsymbol{D}$, and $\boldsymbol{E}$ showing that the ACh-elicited inhibition in the presence of NBQX, APV, and mecamylamine is eliminated by scopolamine $(10 \mu \mathrm{m})$. Paired $t$ tests were performed in $\boldsymbol{B} .{ }^{* *} p<0.01$. Vm, Membrane voltage.

stricted to the target glomeruli, ACh was first puffed to the offtarget glomeruli adjacent to that with the dendrites of the recorded MTC (Fig. 1B). Off-target ACh puffs evoked no response in any tested cells ( $n=5$ cells; Fig. $1 C$, top trace), confirming the restricted action of puffed ACh. ACh puffed into the on-target glomerulus produced a compound response in the recorded MTC consisting of a brief increase in firing followed by an afterhyperpolarization (AHP) that was sufficient to inhibit firing
(Fig. 1C, middle panels). This effect persisted in the presence of the glutamate receptor blockers NBQX and APV (Fig. 1C, bottom panels), indicating that the excitation is not mediated by ionotropic glutamatergic receptors. However, the nAChR blocker mecamylamine $(10 \mu \mathrm{M})$ abolished the ACh-induced enhancement of firing (Fig. $1 D$, red trace) and reduced the hyperpolarization (measured as the integrated voltage change below baseline) by half $(49.9 \pm 6.0 \%, n=5$; Fig. $1 E)$. This indicates that 
the brief excitation of MTCs is due to the activation of nAChRs. Nicotinic excitation of MTCs triggers feedback inhibition from the glomerular circuit (D'Souza and Vijayaraghavan, 2012). However, the $50 \%$ AHP reduction by mecamylamine observed here cannot be attributed to the blocking of inhibitory feedback because it occurred in the presence of NBQX and APV, which block the MTC excitatory drive on local glomerular interneurons. Rather, nAChR-mediated, high-frequency spiking triggers an intrinsic MTC membrane AHP, and mecamylamine, by blocking the high-frequency firing, eliminates this component of the AHP. The remaining $50 \%$ of the AHP was completely blocked by scopolamine ( $1.4 \pm 0.4 \%$ of control, $n=5$; Fig. $1 D, E)$, a broad-spectrum antagonist of $\mathrm{mAChRs}$ in the presence of ionotropic GluR blockers. These results suggest that mAChRs mediate $\sim 50 \%$ of inhibition following the nAChR-mediated excitation in MTCs.

This mAChR-mediated inhibition may be due to several sites of action, as follows: (1) direct mAChR action in MTCs; (2) direct activation of glomerular interneurons to increase GABA release onto MTCs; (3) or both. To explore these possibilities, the selective $\mathrm{GABA}_{\mathrm{A}} \mathrm{R}$ blocker GBZ $(10 \mu \mathrm{M})$ was used to eliminate GABA action. GBZ had no effect on nAChR-mediated excitation of MTCs (nAChR-evoked spiking frequency, $89.5 \pm 9.3$ and $83.6 \pm$ $15.4 \mathrm{~Hz}$, respectively, before and after GBZ application; $n=5$ ) but reduced the AHP to $51.1 \pm 6.6 \%$ of control $(n=5$; Fig. $1 E)$. The presence of NBQX, APV, and GBZ to block both excitatory and inhibitory inputs allowed us to test whether there is direct $\mathrm{mAChR}$ action in MTCs. However, in this condition scopolamine affected neither the nAChR firing nor the remaining AHP $(51.5 \pm 6.5 \%$ of control; Fig. $1 E)$, suggesting that MTCs lack functional $\mathrm{mAChRs}$. Similar results were obtained when scopolamine was applied before GBZ (Fig. 1E), indicating that $\mathrm{mAChR}$ action is mediated by GABA released from local interneurons. The addition of mecamylamine in the presence of scopolamine and GBZ abolished both the brief firing and the remaining AHP $(1.6 \pm 0.3 \%$ of control; $n=5$; Fig. $1 E)$. These results show that ACh puffs, restricted to a single, targeted glomerulus, directly excite MTC apical dendrites via nAChRs. This excitation is followed by inhibition, which consists of the following two components of AHP: one reflects an intrinsic membrane property of MTCs following direct nAChR-mediated spiking; and the other results from an indirect effect on MTC membrane potential following direct $\mathrm{mAChR}$ action on GABAergic glomerular interneurons. Consistent with direct nAChR excitation of MTCs, glomerular ACh evoked a brief inward current (135.6 $\pm 4.2 \mathrm{pA}$; holding potential, $-60 \mathrm{mV} ; n=5$; Fig. $1 F$ ) followed by an outward current in the presence of NBQX and APV. Mecamylamine abolished the inward current but not the outward current (Fig. $1 F, G$, red traces), which was blocked by subsequent application of scopolamine (control, $102.6 \pm 11.0 \mathrm{pA} / \mathrm{s}$; scopolamine, $2.2 \pm$ $0.4 \mathrm{pA} / \mathrm{s} ; n=5, p<0.001$; Fig. $1 G, H$ ) or GBZ (control, $103.7 \pm$ $14.3 \mathrm{pA} / \mathrm{s}$; GBZ, $3.9 \pm 0.7 \mathrm{pA} / \mathrm{s} ; n=5, p<0.001$; Fig. $1 H)$. Together, these results are consistent with the hypothesis that ACh directly activates nAChRs on MTCs, and mAChRs on glomerular inhibitory interneurons.

This hypothesis predicts that glomerular ACh should enhance GABAergic inhibition of MTCs. To test this, sIPSCs were recorded from MTCs voltage clamped at $0 \mathrm{mV}$ in the presence of NBQX and APV (Fig. 1I). As shown by Figure 1, $I$ and $J$, ACh micropuffed into the target glomerulus reproducibly enhanced both amplitude ( $263.1 \pm 28.1 \%$ of control; $n=5)$ and frequency (452. $\pm 101.4 \%$ of control; $n=5$ ) of sIPSCs in MTCs (Fig. $1 \mathrm{~J}, K$ ). sIPSC enhancement was completely eliminated by scopolamine
(97.2 \pm 6.0 of control amplitude and $106.2 \pm 4.6 \%$ of control frequency; $n=5$ ) but was not affected by mecamylamine $(270.2 \pm 29.9 \%$ of control amplitude and $446.5 \pm 97.5 \%$ of control frequency; $n=5$ ). This supports the hypothesis that ACh activation of $\mathrm{mAChR}$ enhances the GABAergic glomerular inhibition of MTCs.

\section{Optogenetic stimulation of cholinergic fibers in glomeruli}

In an effort to assess the actions of endogenously released ACh on MTCs in slices, we turned to an optogenetic approach, which we have used for other glomerular neurons, including TH-cre SACs (Liu et al., 2013), and GAD65-cre PGCs and CCK-cre superficial tufted cells (our unpublished observations). Several strategies were tried, as follows: viral expression of ChR2 in DB creexpressing cholinergic neurons using single or multiple AAV serotypes or transgenic mice expressing $\mathrm{ChR} 2$ under control of the ChAT promoter (ChAT-ChR2 mice). All of these approaches yielded negligible to sparse ChR2 fiber density in glomeruli following survival times ranging from 2 to 12 weeks (>60 mice) despite robust ChR2 expression in DB neurons themselves and prominent $\mathrm{ChR} 2$ processes in deeper OB layers.

Light stimulation robustly excited all $\mathrm{DB} \mathrm{ChR} 2{ }^{+}$neurons tested (12 of 12 neurons), indicating that ChR2 was strongly expressed and functional. To assess the optical activation of ChAT-ChR2 fibers on MTCs, a candidate MTC was filled with fluorescent dye to see whether its dendrite entered a glomerulus with ChR2 fibers. MTCs were filled until a candidate "fit" was obtained. In slices from 52 mice with confirmed fits, optical stimulation of glomeruli generated no response in 155 of 175 MTCs tested and weak, variable responses in 20 cells. In each case, we raised the laser power to as high as $50 \mathrm{~mW}$ to ensure sufficient activation of the ChR expressed in cholinergic fiber terminals. But this high-power optical stimulation did not evoke more responses.

What might account for the lack of responsive MTCs? Mouse glomeruli are $\sim 50-100 \mu \mathrm{m}$ in diameter, and, at most, 25 MTCs project to each glomerulus. Given the "sparseness" of ChR2 fibers in even the "best" glomeruli, a filled MTC has a very low probability of receiving ChR2 synaptic inputs. Glomeruli also contain many more local interneurons than MTCs ( 350 interneurons per glomerulus; Parrish-Aungst, 2007). Thus, sparse ChR2-expressing cholinergic axons may target only a small subset of a large number of glomerular neurons. Finding a patched, filled MTC synaptically targeted by $\mathrm{ChR} 2$ axons is likely a rare event. Alternatively, there may simply be too little ChR2 in axons to allow for activation, although we used laser power intensity in a sequence up to $50 \mathrm{~mW}$, so insufficient laser activation energy can be ruled out. Therefore, to assess the cholinergic modulation of glomerular neurons, we used selective, glomerulus-limited micropuff application of ACh.

\section{ACh modulates the activity of external tufted cells}

ETCs are key excitatory neurons that gate glomerular output; they receive direct ON inputs (Hayar et al., 2004a; Liu and Shipley, 2008a) and make glutamatergic synapses onto MTCs (Gire et al., 2012; Shao et al., 2012) as well as to GABAergic interneurons including PGCs and SACs (Hayar et al., 2004a; Shao et al., 2012). Cholinergic inputs directly activate nAChRs on ETCs (D'Souza et al., 2013), but it is not known whether ETCs are directly modulated by mAChRs. To investigate this, ACh (1 mM, $1 \mathrm{~s})$ was micropuffed into a glomerulus while recording ETCs clamped at $-60 \mathrm{mV}$ in the presence of NBQX, APV, and GBZ to eliminate circuit effects. ACh produced an inward current (27.8 $\pm 5.3 \mathrm{pA}, n=5$; Fig. $2 A)$ that was blocked by mecamyl- 
A

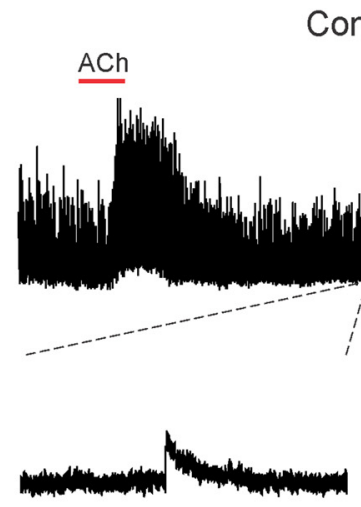

C

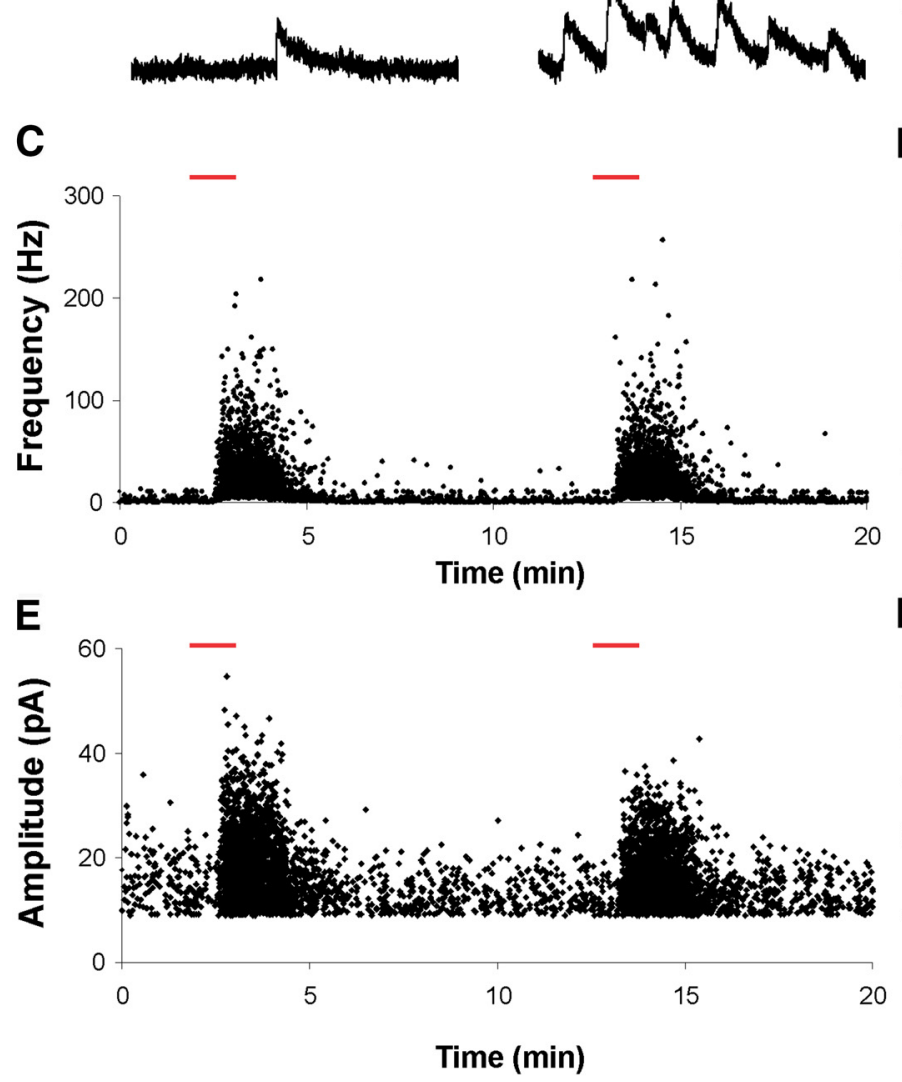

E

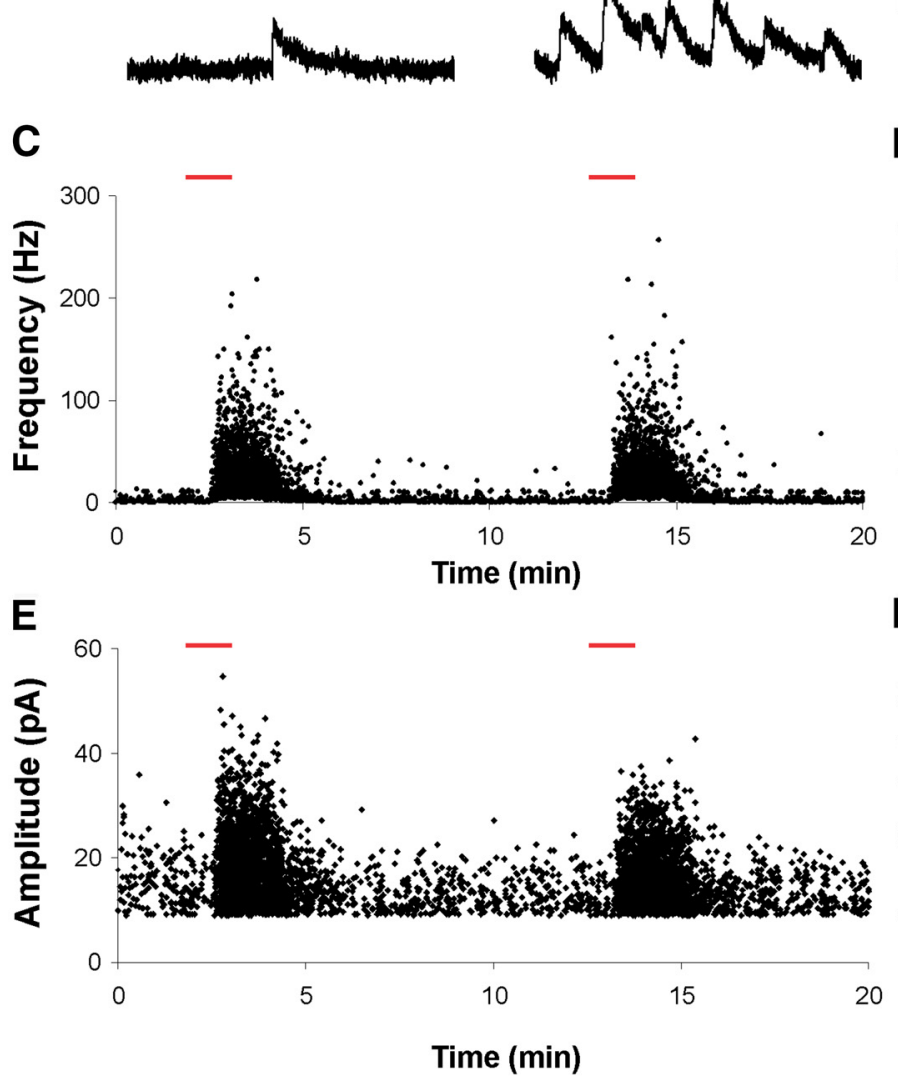

B

+ Scopolamine

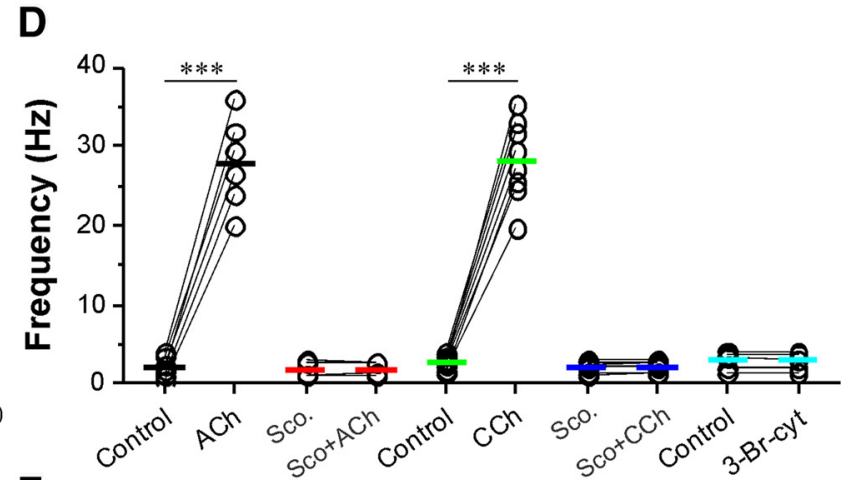

$\mathbf{F}$

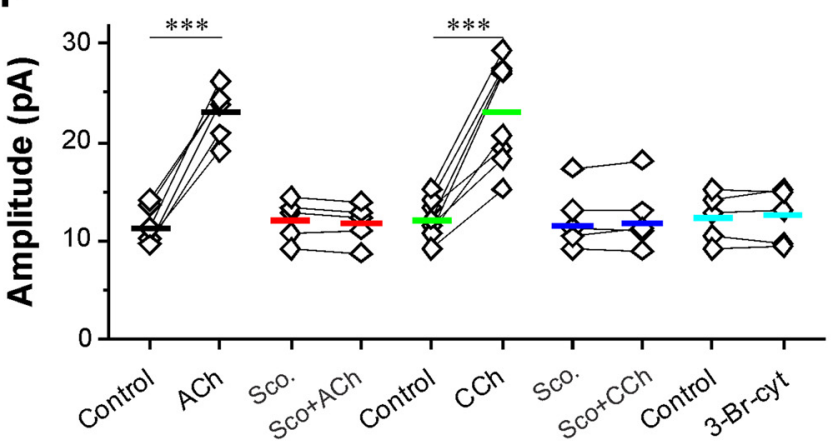

Figure 3. ACh via mAChRs enhances sIPSCs in ETCs. A, Top, Voltage-clamp trace showing that bath-applied ACh (200 $\mu \mathrm{m}, 2$ min, red bar) enhances sIPSCs in ETCs. Bottom, Blow-up from $\boldsymbol{A}$ showing sIPSCs before and after ACh. B, Voltage-clamp trace from the same cell showing the ACh-induced sIPSC enhancement is eliminated by bath-applied scopolamine (10 $\mu \mathrm{M})$. C, E, Scatter plots from the top trace in $\boldsymbol{A}$ showing that both the frequency $(\boldsymbol{C})$ and amplitude $(\boldsymbol{E})$ of sIPSCs are reproducibly enhanced by $A C h . \boldsymbol{D}, \boldsymbol{F}$, Quantification data showing that the $A C h$-induced or $20 \mu \mathrm{m}$ CCh-induced enhancement of both frequency $(\boldsymbol{D})$ and amplitude ( $\boldsymbol{F}$ ) of sIPSCs is eliminated by scopolamine (Sc0., $10 \mu \mathrm{m}$ ), and that the nAChR activator 3-Br-cytisine ( $5 \mu \mathrm{m})$ does not alter sIPSCs in ETCs. Paired $t$ tests were performed in $\boldsymbol{D}$ and $\boldsymbol{F}$. ${ }^{* *} p<0.001$.

amine $(0.8 \pm 0.2 \mathrm{pA} ; n=5, p<0.001$; Fig. $2 B)$, confirming direct $\mathrm{nAChR}$ activation. Moreover, the addition of scopolamine showed no effect (data not shown). This suggests that ETCs are not modulated by direct $\mathrm{mAChR}$ activation.

To see whether ETCs are indirectly modulated by the activation of mAChRs on glomerular inhibitory interneurons, spontaneous action potentials were recorded from ETCs in current clamp and ACh was puffed into glomerulus. Consistent with the direct nAChR excitation, ACh caused a brief enhancement of spontaneous spikes in all tested ETCs (Fig. $2 C ; n=6$ ). The addition of NBQX and APV in the bath to block fast glutamatergic inputs did not affect the ACh-induced spike burst but revealed a prominent inhibition following the excitation ( $n=6$; Fig. $2 D)$. Mecamylamine abolished the brief excitation but not the inhibition (Fig. $2 E ; n=6$ ), which was eliminated by application of scopolamine (Fig. 2F; $n=6$ ). This suggests that ACh directly excites ETCs via nAChRs and indirectly inhibits them by activation of mAChRs on local glomerular interneurons.

\section{Cholinergic modulation of glomerular inhibition}

Our results for MTCs and ETCs suggest that mAChR modulation of the glomerular circuit is mediated by increased local GABA release. If true, $m A C h R$ activation should increase $G_{A B A} R$ mediated postsynaptic inhibition of glomerular neurons. We tested this prediction in several ways.

The primary dendrites of ETCs ramify exclusively in glomeruli (Hayar et al., 2004b; Shao et al., 2012); thus, they serve as useful sensors of glomerular inhibition as they do not receive inhibitory synapses from granule cells. To assess ACh modulation of glomerular inhibition, sIPSCs were recorded in ETCs before and after the application of ACh (Fig. 3A). To optimize sIPSC detection, ETCs were held at $0 \mathrm{mV}$ in the presence of NBQX and APV to eliminate spontaneous EPSCs; $\mathrm{Cs}^{+}$and QX314 were included in the internal solution to further improve the detection of IPSCs. In these conditions, ACh significantly increased both the frequency $(27.9 \pm 2.4 \mathrm{~Hz} \mathrm{ACh}, 2.2 \pm 0.6 \mathrm{~Hz}$ control, $n=6, p<0.001$; Fig. $3 A, C, D)$ and amplitude (23.1 \pm 
$1.1 \mathrm{pA} \mathrm{ACh}, 11.4 \pm 0.8 \mathrm{pA}$ control, $n=6, p<0.001$; Fig. $3 A, E, F)$ of sIPSCs. Scopolamine $(10 \mu \mathrm{M})$ blocked both the increased frequency and amplitude of sIPSCs (frequency: $1.9 \pm 0.4 \mathrm{~Hz}$ scopolamine $+\mathrm{ACh}, 1.8 \pm 0.4 \mathrm{~Hz}$ scopolamine alone, $n=5, p>$ 0.05 , Fig. $3 B, D$; amplitude: $11.8 \pm 0.9 \mathrm{pA}$ scopolamine $+\mathrm{ACh}$, $12.0 \pm 0.9$ pA scopolamine alone, $n=5, p>0.05$, Fig. $3 B, F)$. In all cases, gabazine blocked all IPSCs (data not shown). These results indicate that $\mathrm{ACh}$ acts via $\mathrm{mAChRs}$ on local interneurons to increase GABA release enhancing sIPSCs in ETCs.

$\mathrm{ACh}$ is hydrolyzed by acetylcholinesterase (AChE), and AChE is highly expressed in the glomerular layer (Nickell and Shipley, 1988a). To obviate the potential confounding effects of AChE, we also examined the effect of the nonhydrolyzable cholinergic agonist CCh on sIPSCs. Consistent with the ACh results, CCh (20 $\mu \mathrm{M})$ significantly increased both the frequency and amplitude of sIPSCs, which are indistinguishable from those of ACh itself (frequency: $28.3 \pm 1.8 \mathrm{~Hz}$ in CCh, $2.8 \pm 0.3 \mathrm{~Hz}$ in control, $n=8, p<$ 0.001 , Fig. $3 D$; amplitude: $23.1 \pm 1.9 \mathrm{pA}$ in CCh, $12.1 \pm 0.7 \mathrm{pA}$ in control, $n=8, p<0.001$, Fig. $3 F)$. The actions of CCh were completely blocked by scopolamine (Fig. $3 D, F$ ). In contrast to $\mathrm{ACh}$ and $\mathrm{CCh}$, the selective $\mathrm{nAChR}$ agonist 3 -Br-cytisine ( $5 \mu \mathrm{M})$ altered neither the frequency nor the amplitude of sIPSCs in ETCs (frequency: $2.9 \pm 0.5 \mathrm{~Hz}$ in 3-Br-cytisine, $3.0 \pm 0.5 \mathrm{~Hz}$ in control, $n=5, p>0.05$, Fig. $3 D$; amplitude: $12.5 \pm 1.2 \mathrm{pA}$ in 3-Br-cytisine, $12.3 \pm 1.1 \mathrm{pA}$ in control, $n=5, p>0.05$, Fig. $3 F)$. These findings are all consistent with the interpretation that ACh activates $\mathrm{mAChRs}$ on glomerular interneurons to increase GABA release and increase the postsynaptic inhibition of ETCs.

\section{Muscarinic actions on PGCs and SACs}

G-protein-coupled mAChRs modulate the excitability of many neuron types, including granule cells in the olfactory bulb (Castillo et al., 1999; Pressler et al., 2007; Thiele, 2013). The preceding results show that ACh activation of $\mathrm{mAChRs}$ increases glomerular inhibition of MTCs and ETCs. One potential explanation for this is that the activation of mAChRs directly excites glomerular inhibitory neurons to increase GABA release. To test this, we examined the effects of mAChR activation on PGCs and SACs, the two major GABAergic glomerular interneurons. PGCs and SACs each comprise two subtypes based on their major direct excitatory drive: $\mathrm{ON}$-driven $(\mathrm{ONd})$ subtypes receive monosynaptic ON input; and ET-driven (ETd) subtypes receive monosynaptic input from ETCs (Shao et al., 2009). Previous anatomical studies (Crespo et al., 2000) suggested that mAChRs are present only on ONd subtypes. In current clamp (Fig. $4 A$, left, $B, C$ ), CCh $(20 \mu \mathrm{M})$ hyperpolarized both ONd and ETd subtypes in all PGCs and SACs tested (PGCs: $n=4$ ONd, $n=5$ ETd; SACs: $n=5$ ONd, $n=6$ ETd). Hyperpolarization was completely blocked by scopolamine (10 $\mu \mathrm{M}$; Fig. $4 B, C)$, indicating mediation by mAChRs. In voltage clamp (Fig. $4 \mathrm{~A}$, right, $B, C$ ), glomerular puffs of ACh also produced a hyperpolarizing current in all PGCs and SACs tested. This outward current was abolished by scopolamine. Together, these findings demonstrate that ACh directly inhibits the somas of all PGCs and SACs via mAChRs.

Direct muscarinic inhibition of PGC and SAC cell bodies is seemingly at odds with our observations that ACh causes increased GABA release. However, there is evidence that ACh can alter transmitter release through direct action at dendritic synaptic release sites (Castillo et al., 1999; Ghatpande et al., 2006; Oldenburg and Ding, 2011). Next, we tested this possibility.

\section{$m A C h R s$ increase GABA release in an action potential- independent manner}

Reciprocal dendrodendritic transmission between granule cells and the lateral dendrites of MTCs can be independent of action potentials (Isaacson and Strowbridge, 1998). Dendrodendritic synapses are the principal type of synaptic contact among glomerular neurons (Pinching and Powell, 1971b,c; White, 1973; Kasowski et al., 1999), and glomerular dendrodendritic synaptic interactions may be, at least partially, independent of action potentials in presynaptic neurons (Murphy et al., 2005). PGCs lack an axon and have exclusively dendrodendritic synapses (Kosaka and Kosaka, 2005a,b, 2011). SACs were originally reported as having short axons (Pinching and Powell, 1971a,b,c), but subsequent studies (Aungst et al., 2003; Kiyokage et al., 2010) using newer experimental approaches demonstrated that they had long processes spanning multiple glomeruli. These interglomerular processes have not been definitively identified as axons or dendrites; thus, GABA release from SACs could be axonic, dendritic, or both. Since ACh can act directly at synaptic release sites in the bulb (Castillo et al., 1999; Ghatpande et al., 2006; Oldenburg and Ding, 2011), mAChRs could enhance PGC dendritic or SAC axon/dendrite GABA release independent of their somatic actions.

To explore this, we recorded action potential-independent IPSCs from ETCs, which, along with MTCs, are major targets of PGC and SAC dendrodendritic synapses but, unlike MTCs, receive no granule cell synapses. TTX $(1 \mu \mathrm{M})$ was applied to block action potentials, thus isolating PGC/SAC dendritic synaptic release sites from somatic spiking. In these conditions, CCh (20 $\mu \mathrm{M})$ caused a more than threefold increase in both the frequency and amplitude of IPSCs (frequency: $44.6 \pm 5.0 \mathrm{~Hz}$ in CCh, $14.8 \pm$ $1.9 \mathrm{~Hz}$ in control, $n=5, p<0.001$, Fig. $5 A, B, E$; amplitude: $70.5 \pm 3.8 \mathrm{pA}$ in CCh, $20.4 \pm 1.7 \mathrm{pA}$ in control, $n=5, p<0.001$, Fig. $5 A, C, F)$. The enhancement of IPSCs was completely blocked by scopolamine (Fig. $5 D, E, F$ ). Similar results were observed with ACh (Fig. 5E,F). These findings indicate that ACh activation of mAChRs can increase GABA release from inhibitory interneuron release sites, independent of action potentials.

Similar experiments were extended to PGCs and SACs. As shown by Figure 6, CCh $(20 \mu \mathrm{M})$ increased both the frequency (Fig. 6, top panels) and amplitude (Fig. 6, bottom panels) of IPSCs in all four subtypes of glomerular interneurons. This was not altered by the addition of TTX $(1 \mu \mathrm{M})$ but was completely eliminated by scopolamine $(10 \mu \mathrm{M})$. Together, these findings support the conclusion that the activation of mAChRs increases GABA release at dendrodendritic synapses of glomerular interneurons to enhance glomerular inhibition.

\section{mAChRs enhance presynaptic inhibition of $\mathrm{ON}$ terminals}

The activation of $\mathrm{mAChRs}$ increases GABA release from the dendrites of glomerular inhibitory interneurons. Elevated GABA levels might activate $\mathrm{GABA}_{\mathrm{B}}$ receptors on olfactory nerve terminals to suppress synaptic transmitter release from the terminals (i.e., presynaptic inhibition; McGann et al., 2005; Wachowiak et al., 2005; Vucinic et al., 2006; Pírez and Wachowiak, 2008; Shao et al., 2009). Indeed, glomerular ACh micropuffs reproducibly decreased the amplitude of ON-evoked EPSCs in ETCs by 23\% (Fig. $7 A-D ; n=11, p<0.001)$. This was completely eliminated by scopolamine $(n=5, p>0.05$; Fig. $7 D)$, indicating mediation by mAChRs. The selective $\mathrm{GABA}_{\mathrm{B}}$ receptor antagonist CGP55845 $(10 \mu \mathrm{M})$ increased ON-ETC EPSCs by $19 \%(119.2 \pm 6.5 \%$ of control, $n=5$ ), which is consistent with previous in vivo and in vitro studies showing that tonic presynaptic inhibition of $\mathrm{ON}$ terminals is mediated by $\mathrm{GABA}_{\mathrm{B}}$ Rs (McGann et al., 2005; Wa- 
A

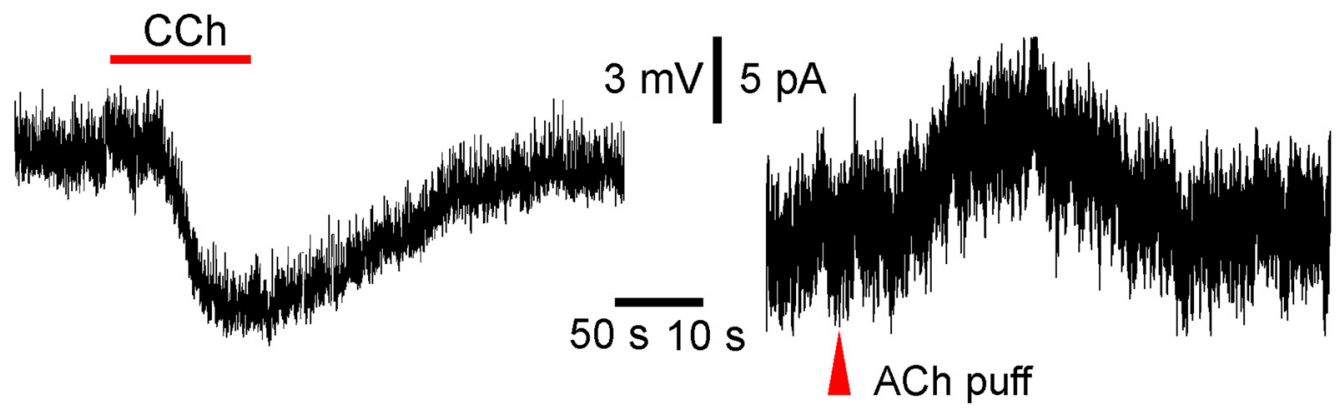

B

ON-d

PGCs
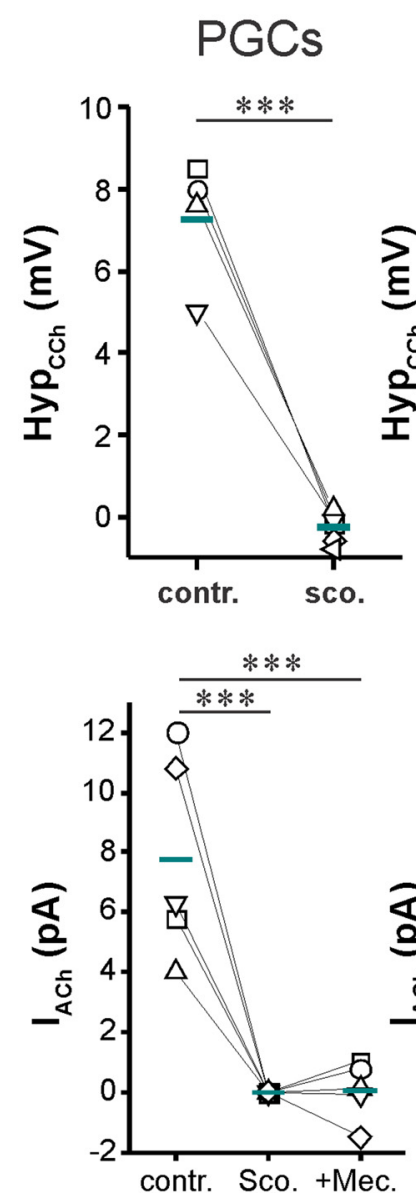

SACS

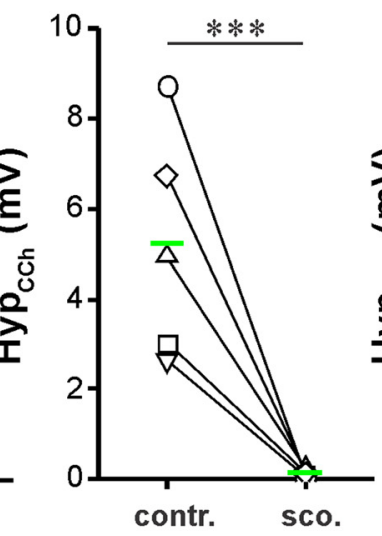

C

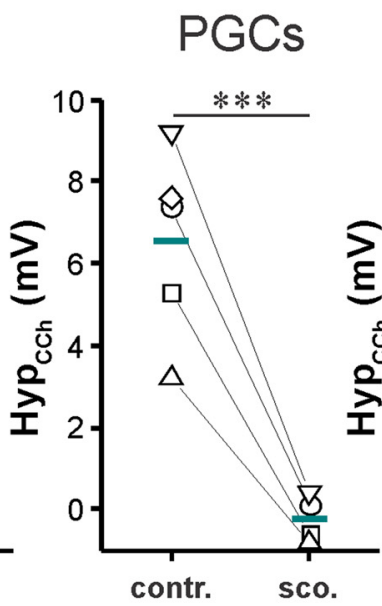

ET-d
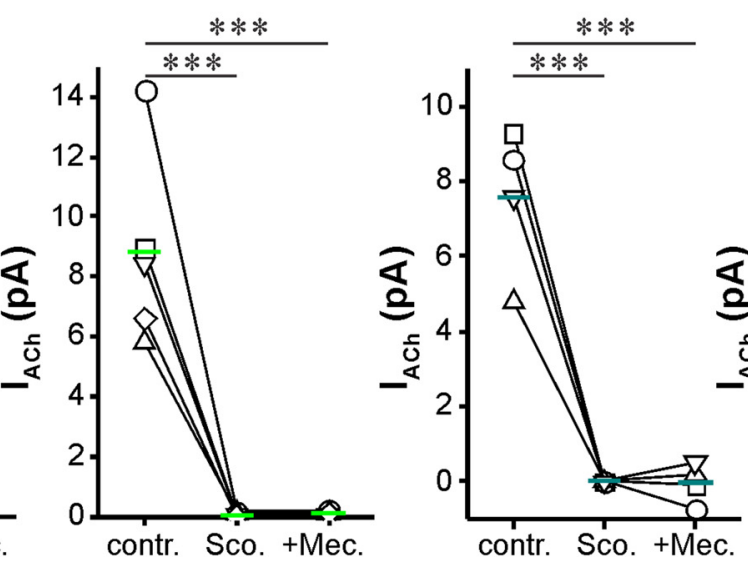

SACS

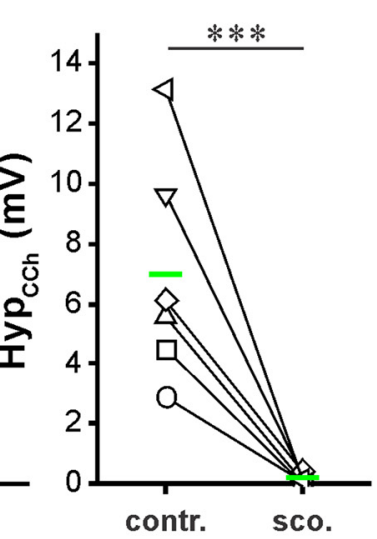

Figure 4. Activation of $\mathrm{mAChRs} \mathrm{inhibits} \mathrm{PGCs} \mathrm{and} \mathrm{SACS.} \mathrm{A,} \mathrm{Somatic} \mathrm{recordings} \mathrm{in} \mathrm{current} \mathrm{clamp} \mathrm{(left)} \mathrm{or} \mathrm{voltage} \mathrm{clamp} \mathrm{(right)} \mathrm{from} \mathrm{a} \mathrm{TH-GFP-labeled} \mathrm{SAC} \mathrm{showing} \mathrm{that} \mathrm{bath-applied} \mathrm{CCh} \mathrm{(20} \mu \mathrm{M}$ ) produces hyperpolarization and glomerular micropuffing of ACh (red arrowhead, $1 \mathrm{~mm}, 1 \mathrm{~s}$ ), produced an outward current when the cell was held at $-60 \mathrm{mV}$ in the presence NBQX ( $10 \mu \mathrm{M}$ ), APV ( 50 $\mu \mathrm{M})$, and GBZ (10 $\mu \mathrm{M})$ to eliminate the circuit effect. B, C, Quantification data showing that CCh-induced hyperpolarization or ACh-induced outward current was observed in all tested ONd (B) and ETd (C) PGCS and SACs, and these effects were completely eliminated by scopolamine $(10 \mu \mathrm{m})$. Paired $t$ test and repeated-measures ANOVA were performed for current-clamp results (top graphs in $\boldsymbol{B}$ ) and voltage-clamp results (bottom graphs in $\boldsymbol{B}$ ), respectively. ${ }^{* *} p<0.001$. contr., Control; sco., scopolamine; mec., mecamylamine.

chowiak et al., 2005; Pírez and Wachowiak, 2008; Shao et al., 2009). Finally, CGP55845 prevented the reduction by ACh of ON-evoked EPSCs in ETCs $(119.1 \pm 5.3 \%$ in CGP55845, $n=5$, $p>0.05$; Fig. 7D). This indicates that ACh increases GABA release from glomerular interneurons and reduces ON-ETC transmission by activating $\mathrm{GABA}_{\mathrm{B}}$ receptors on sensory terminals.

Collectively, our findings support the hypothesis that ACh directly activates $\mathrm{mAChRs}$ on glomerular inhibitory interneuron dendrodendritic synapses to increase GABA release. This results in $\mathrm{GABA}_{\mathrm{A}}$ receptor-mediated postsynaptic inhibition of MTCs and ETCs, and $\mathrm{GABA}_{\mathrm{B}}$ receptor-mediated presynaptic inhibition of ON terminals. These mAChR-mediated inhibitory actions sculpt the input-output function of glomerular circuitry.

\section{Discussion}

The present findings demonstrate that ACh modulates OB output neurons by activating nicotinic and muscarinic receptors at multiple sites in the glomerular circuit. Specifically, ACh produces excitation followed by a relatively long duration of inhibition in MTCs and ETCs, the two principal glomerulus output 
A

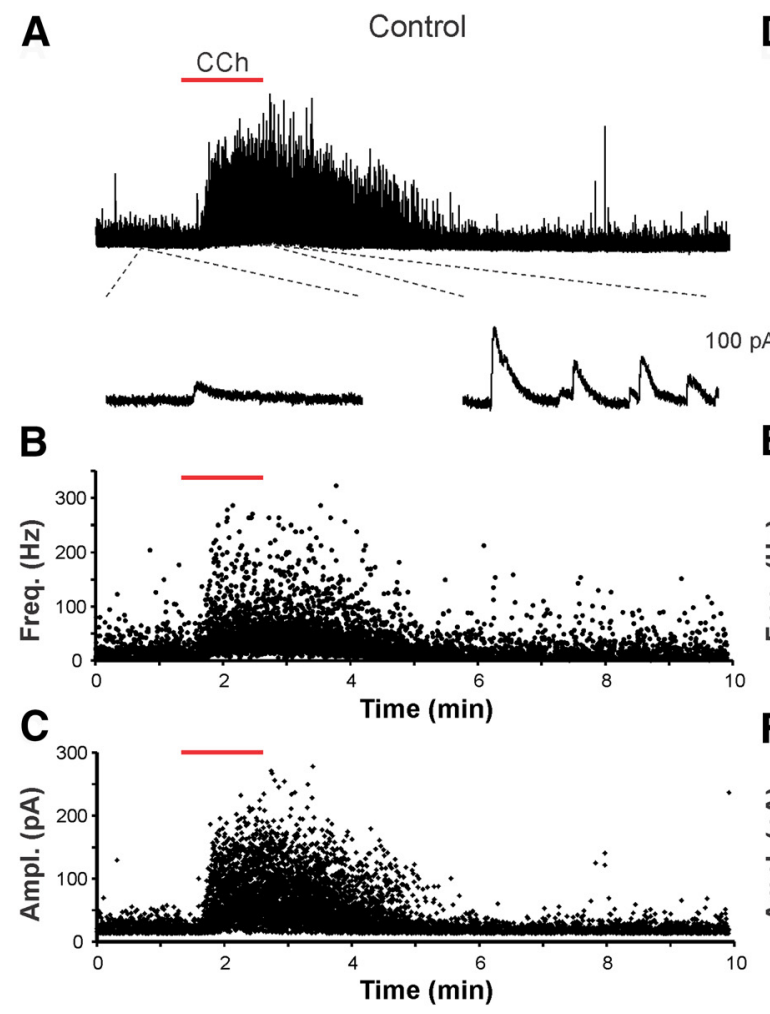

D

Scopolamine

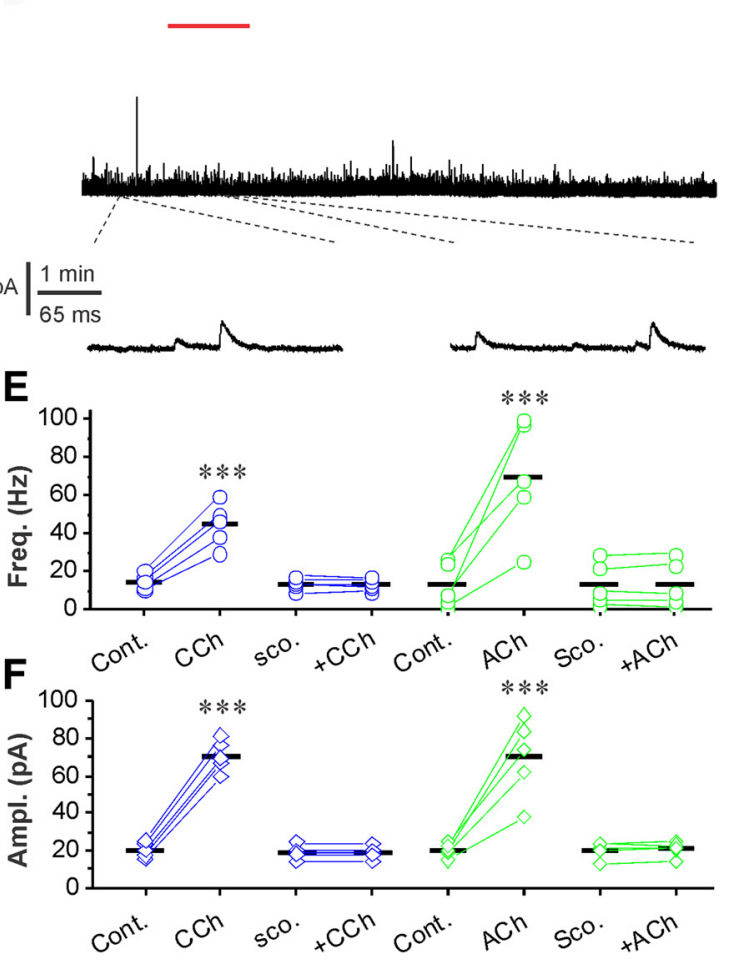

Figure 5. Activation of mAChRs enhances mIPSCs in ETCS. A, Top, Voltage-clamp trace showing that bath-applied CCh ( $20 \mu \mathrm{M}$, red bar) enhances mIPSCs when the ETC was held at $0 \mathrm{mV}$ in the presence of NBQX (10 $\mu \mathrm{M}), A P V(50 \mu \mathrm{M})$, and TTX $(1 \mu \mathrm{M})$. Bottom, Blow up from the top trace showing changes in mIPSCs before and after CCh administration. B, C, Scatter plots from the top trace in $\boldsymbol{A}$ showing that both frequency (Freq.; $\boldsymbol{B}$ ) and amplitude (Ampl.; $\boldsymbol{C}$ ) $\mathrm{O}$ mIPSCs were enhanced by $\mathbf{C}(\mathrm{C}$. $\boldsymbol{D}$, Voltage-clamp traces from the same cell in $\boldsymbol{A}$ showing that the CCh-induced enhancement of mIPSCs was completely blocked by bath-applied scopolamine (scop.; $10 \mu \mathrm{M})$. $\boldsymbol{E}, \boldsymbol{F}$, Quantification data from five cells showing that either CCh or ACh (200 $\mu \mathrm{M})$ enhances both the frequency $(\boldsymbol{E})$ and amplitude $(\boldsymbol{F})$ of mIPSCs in all tested ETCs, and that these effects were completely eliminated by scopolamine. Repeated-measures ANOVA was performed in $\boldsymbol{E}$. ${ }^{* * *} p<0.001$. Cont., Control.

neurons. Excitation is due to direct activation of nAChRs on MTCs and ETCs. The inhibition is mediated by GABA release due to direct $\mathrm{mAChR}$ activation of dendritic synapses of PGCs and SACs, the two principal glomerular inhibitory interneurons. In addition, nAChR excitation of ETCs and MTCs triggers inhibitory feedback from PGCs and SACs. Increased GABA release also causes presynaptic inhibition of the first synapse in the olfactory system. Thus, basal forebrain cholinergic projections act via both nicotinic and muscarinic receptors in the glomerular circuit to sculpt $\mathrm{OB}$ output to downstream olfactory networks.

\section{Comparison with in vivo findings}

Previous in vivo physiological studies assessed centrifugal ACh modulation of olfaction by electrical or optogenetic stimulation of the DB neurons (Inokuchi et al., 1987; Nickell and Shipley, 1988b; Kunze et al., 1991; Ma and Luo, 2012; Zhan et al., 2013). DB projection neurons are heterogeneous as regards transmitters (Zaborszky et al., 1986, 2012) and project to OB as well as other cortical circuits interconnecting with the $\mathrm{OB}$ (Shipley and Adamek, 1984; Woolf et al., 1984; Zaborszky et al., 1986, 2012; Boyd et al., 2012; Markopoulos et al., 2012). Discrepant results have been reported with DB stimulation (Inokuchi et al., 1987; Kunze et al., 1991; Ma and Luo, 2012; Zhan et al., 2013). A recent in vivo optogenetic study (Rothermel et al., 2014) selectively targeted cholinergic inputs to OB by activating ChR2 axons/terminals of gene-targeted DB cholinergic neurons within $\mathrm{OB}$. Consistent with the nAChR-mediated excitation in the present slice experiments, optogenetic activation of cholinergic fibers in the OB evoked the excitation of MTCs (Rothermel et al., 2014). However, in contrast to the mAChR-mediated inhibition re- ported here, inhibitory modulation was not seen in vivo. What might account for this discrepancy? It seems unlikely that nAChR-mediated excitation prevails over mAChR-mediated inhibition during the long-duration (5 s) optical stimulation used in vivo because nAChRs desensitize rapidly (Quick and Lester, 2002; Giniatullin et al., 2005; Dani and Bertrand, 2007). One possibility is that inhibitory modulation may have been present but undetected by extracellular recordings. Another possibility is that $\mathrm{mAChR}$ activation increases GABA release sufficient to inhibit local GABAergic interneurons; consistent with this, we found that the activation of mAChRs increased sIPSCs in both PGCs and SACs. Due to tonic glomerular inhibition of MTCs (Pírez and Wachowiak, 2008; Shao et al., 2012), mAChRmediated inhibition of glomerular inhibitory neurons (Ma and Luo, 2012) might "disinhibit" MTCs, resulting in net excitation. It is also possible that laser light delivered to the surface of $\mathrm{OB}$ in vivo (Rothermel et al., 2014) activated deeper cholinergic terminals to inhibit GCs via mAChRs. This could disinhibit MTCs, as reported in OB slices (Castillo et al., 1999), increasing their excitation. Finally, it is possible that optogenetic activation of cholinergic terminals in $\mathrm{OB}$ triggers the corelease of unknown transmitters or neuropeptides (Senut et al., 1989; Arrigoni and Saper, 2014) that excite MTCs.

\section{Muscarinic enhancement of glomerular inhibition}

Cholinergic inputs from the DB are thought to mainly target inhibitory OB interneurons (Kasa et al., 1995), including GCs and glomerular interneurons. Activation of mAChRs alters the excitability of OB GCs (Castillo et al., 1999; Ghatpande et al., 2006; Pressler et al., 2007; Ghatpande and Gelperin, 2009). Here 
A
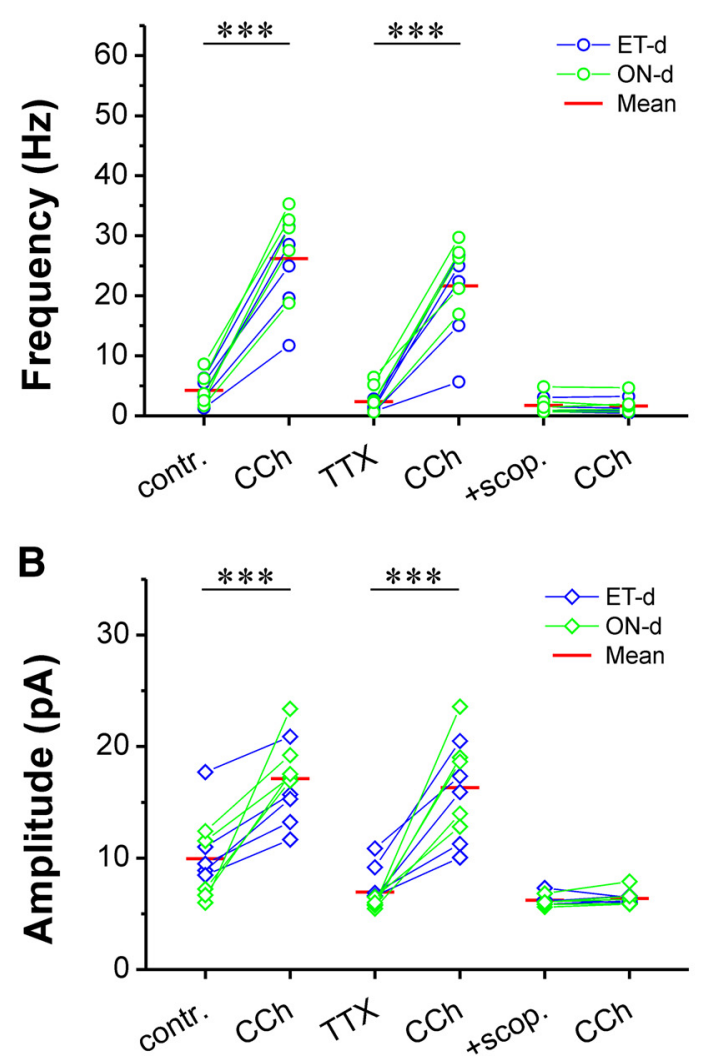

SACs
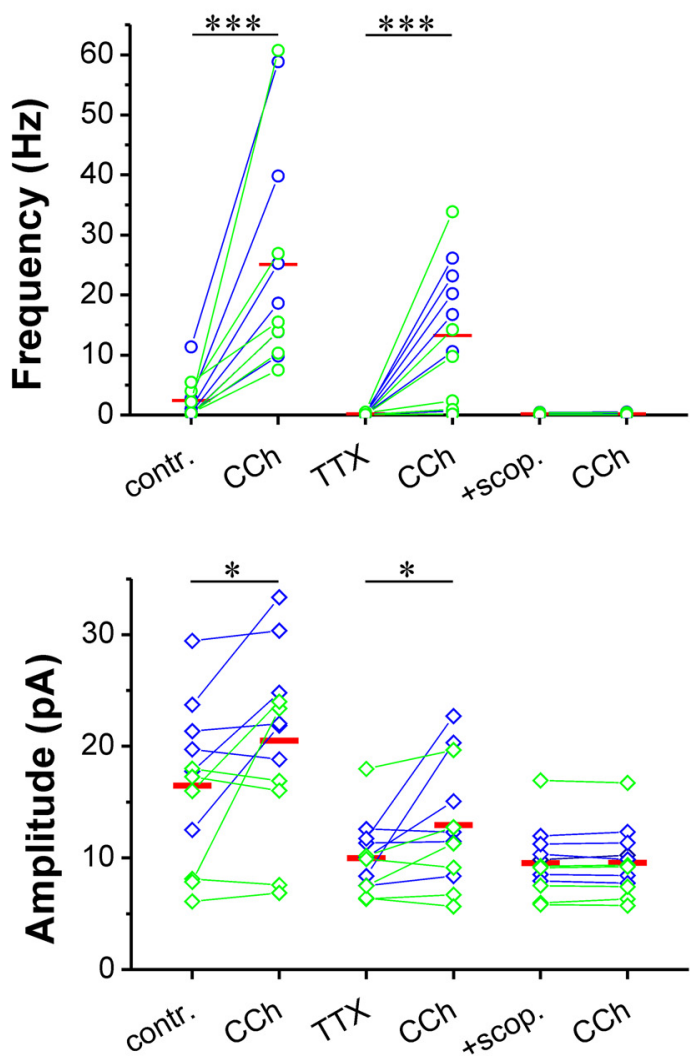

Figure 6. Activation of mAChRs enhances sIPSCS and mIPSCs in both PGCs and SACs. A, Bath-applied CCh enhances the frequency (top graphs) of sIPSCS (contr.) and mIPSCs (TTX) in both PGCs (left graphs) and SACs (right graphs), and these effects were completely blocked by bath-applied scopolamine (scop.; $10 \mu \mathrm{M}$ ). $\boldsymbol{B}$, Bath-applied CCh enhances amplitude (bottom graphs) of sIPSCs (contr.) and mIPSCs (TTX) in both PGCs (left graphs) and SACs (right graphs), and these effects were completely blocked by bath-applied scopolamine $(10 \mu \mathrm{M})$. Paired $t$ test was applied. ${ }^{* * *} p<0.001,{ }^{*} p<$ 0.05 .

we show that the activation of mAChRs enhances glomerular inhibition, which suppresses MTC and ETC spiking, following initial nAChR-mediated excitation. The $\mathrm{GABA}_{\mathrm{A}}$ receptor dependency of MTC and ETC inhibition indicates that mAChRs increase GABA release from glomerular interneurons rather than by direct mAChR action on MTCs and ETCs. This is further supported by the finding that the selective activation of glomerular mAChRs enhances spontaneous IPSCs in MTCs and all glomerular interneurons tested, including ETCs, PGCs, and SACs.

\section{How might $\mathrm{mAChR}$ activation increase intraglomerular GABA release?}

Consistent with previous studies (Pignatelli and Belluzzi, 2008; Ma and Luo, 2012), we found that mAChR activation caused somatic hyperpolarization of both PGCs and SACs. How might this be reconciled with our finding that $\mathrm{mAChR}$ activation increases GABA release? One possibility is that muscarinic receptors increase GABA release by direct actions at PGC dendritic and SAC dendritic/axonal release sites independent of action potential generation at the soma. This possibility is strongly supported by our finding that mAChR activation increased IPSCs in postsynaptic target neurons in the presence of TTX, which blocks action potentials. The mechanisms of differential mAChR modulation of somatic and dendritic/axonal excitability remains to be elucidated, but there are several possibilities. First, different mAChR subtypes may be expressed on the cell bodies and dendritic/axonal release sites of glomerular interneurons. Second, somatic and dendritic/axonal mAChRs may have different post- receptor effector mechanisms. G-protein-coupled mAChRs activate a variety of downstream membrane protein targets that may be distributed into different subcellular compartments (Thiele, 2013). For example, the activation of mAChRs in hippocampal pyramidal neurons engages the PKC pathway, leading to enhanced activation of R-type $\mathrm{Ca}^{2+}$ channels (Tai et al., 2006) and decreased activation of $\mathrm{Na}^{+}$channels (Chen et al., 2005), which are predominantly localized in dendrites and somas/axons, respectively. In accessory olfactory bulb granule cells, the activation of mAChRs closes KCNQ channels, which are preferentially expressed in dendrites to increase dendritic GABA release (Takahashi and Kaba, 2010). Third, mAChRs could release calcium from calcium stores at PGC or SAC dendrodendritic and/or axodendritic synapses or could increase GABA release by modulating "retrograde" regulation of GABA release. Fourth, GABA release from inhibitory interneurons other than PGCs and SACs could potentially contribute to the $\mathrm{mAChR}$ modulation in the glomerular circuit. For example, the terminals of a small population of deep short axon cells that project to the glomerular layer (Eyre et al., 2008) might be modulated by mAChRs. Further studies are needed to distinguish among these and other possibilities, but the results of the present experiments demonstrate clearly that the selective activation of intraglomerular $\mathrm{mAChRs}$ increases GABA release, which increases IPSCs in OB output neurons. These findings raise questions about what it means for a glomerular neuron to be "inhibited," as the hyperpolarization of PGC/SAC cell bodies occurred simultane- 
ously with enhanced synaptic release from their dendrites. This suggests a need for caution in drawing conclusions about dendrodendritic or axodendritic synaptic events based solely on measures of somatic "excitability" or "suppression."

Each $\mathrm{OB}$ glomerulus receives inputs from olfactory sensory neurons expressing the same odorant receptor, and serves as an anatomical and functional unit. Different odorants activate distinct combinations of glomeruli, giving rise to the concept that odors are encoded, initially, as combinatorial patterns of activated glomeruli. Glomeruli are also the first site of synaptic integration in the olfactory system, so that the modulation of glomerular function shapes odor representations in all downstream olfactory networks. Thus, cholinergic modulation of glomerular circuits could impact odor detection and discrimination, as has been reported in behavioral studies (Roman et al., 1993; Ravel et al., 1994; Doty et al., 1999; De Rosa et al., 2001; Fletcher and Wilson, 2002; Mandairon et al., 2006; Chaudhury et al., 2009).

Cholinergic inputs to the $\mathrm{OB}$ (Price and Powell, 1970; Wenk et al., 1977; de Olmos et al., 1978; Macrides et al., 1981; Zaborszky et al., 1986, 2012; Nickell and Shipley, 1988a) target different OB neuron types and different types of AChRs (Le Jeune et al., 1995; Crespo et al., 2000), implying multiple potential functional consequences in vivo. For example, nAChRmediated excitation of ETCs and MTCs could bring the membrane potential of these neurons closer to the firing threshold and could increase their responsiveness to sensory input. However, sustained cholinergic activity-for example during periods of heightened attention-could lead to reduced MTC excitation due to rapid desensitization of nAChRs. Moreover, the activation of mAChRs may lead to subsequent inhibition via GABAergic glomerular circuits. This could reduce spontaneous activity and potentially could filter responses to weak odor inputs. In vivo studies (Ma and Luo, 2012; Rothermel et al., 2014) have reported both increases and decreases in baseline MTC excitation and odorant-evoked responses following the activation of cholinergic inputs to MOB.

Ultimately, the impact of cholinergic modulation on MTC output may depend on tonic levels of excitation and inhibition within OB circuits, tonic levels of basal forebrain cholinergic input to the $\mathrm{OB}$, and the dynamics of cholinergic input during behavior. At present, little is known about these parameters. Cholinergic basal forebrain neurons show both transient spike bursts and slower

A

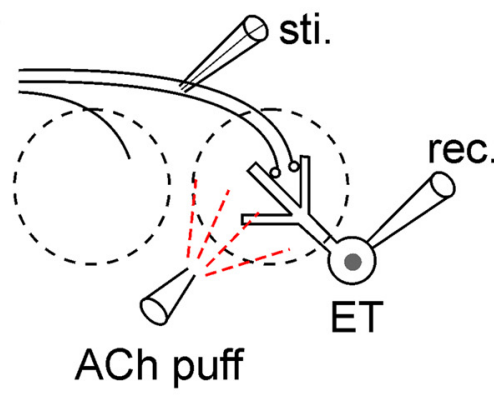

B
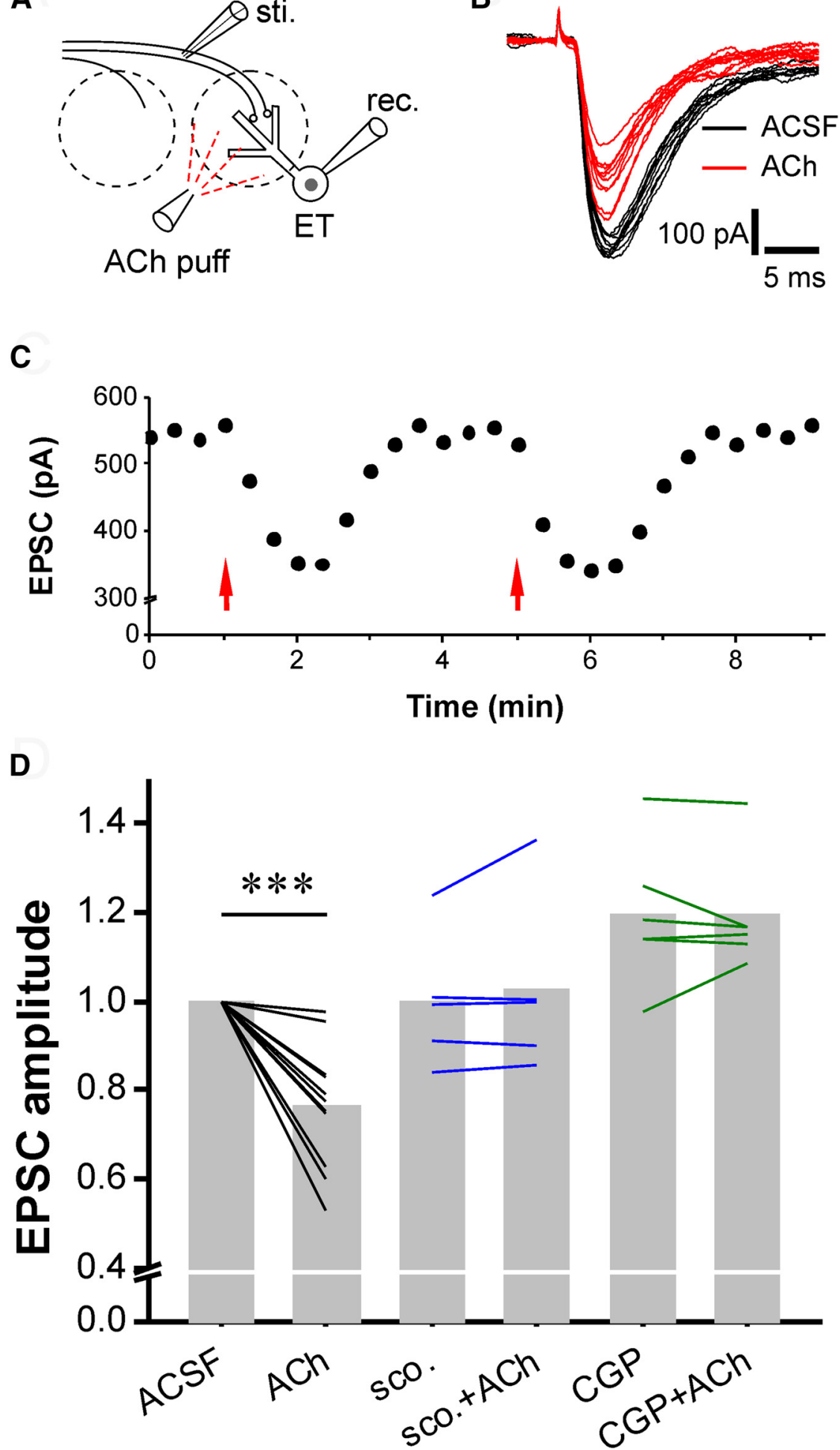

Figure 7. Glomerular ACh enhances the presynaptic inhibition of ON-ETC transmission. $A$, Simplified sketch showing experimental design. $\boldsymbol{B}, 0 \mathrm{~N}$-evoked EPSCsin ETCs before (black) and after (red) micropuffing of ACh (1 mm, 1s). C, Scatter plot showing that ACh reversibly and reproducibly reduces the amplitude of ON-ETC EPSCS. D, Quantification data showing the ACh-induced reduction of ON-ETC EPSC amplitude was completely blocked by bath application of either the mAChR antagonist scopolamine (scop.; $10 \mu \mathrm{M}$ ) or GABA ${ }_{B}$ receptor antagonist CGP55845 (10 $\mu$ m). Paired $t$ test was applied. sti., Stimulus; rec. receptor. ${ }^{* * *} p<0.001$.

changes in mean firing rate during wakefulness (Lee et al., 2005). By mediating both increased excitation and suppression of MTC firing, depending on the mode of basal forebrain neuron activity, cholinergic modulation of OB output may optimize the representation of odor information differentially 
depending on the behavioral context. Improved understanding of cholinergic modulation of olfactory bulb circuits may require recordings of basal forebrain cholinergic neurons in behaving animals.

\section{References}

Antal M, Eyre M, Finklea B, Nusser Z (2006) External tufted cells in the main olfactory bulb form two distinct subpopulations. Eur J Neurosci 24:1124-1136. CrossRef Medline

Arrigoni E, Saper CB (2014) What optogenetic stimulation is telling us (and failing to tell us) about fast neurotransmitters and neuromodulators in brain circuits for wake-sleep regulation. Curr Opin Neurobiol 29:165171. CrossRef Medline

Aungst JL, Heyward PM, Puche AC, Karnup SV, Hayar A, Szabo G, Shipley MT (2003) Centre-surround inhibition among olfactory bulb glomeruli. Nature 426:623-629. CrossRef Medline

Boyd AM, Sturgill JF, Poo C, Isaacson JS (2012) Cortical feedback control of olfactory bulb circuits. Neuron 76:1161-1174. CrossRef Medline

Castillo PE, Carleton A, Vincent JD, Lledo PM (1999) Multiple and opposing roles of cholinergic transmission in the main olfactory bulb. J Neurosci 19:9180-9191. Medline

Chaudhury D, Escanilla O, Linster C (2009) Bulbar acetylcholine enhances neural and perceptual odor discrimination. J Neurosci 29:52-60. CrossRef Medline

Chen Y, Cantrell AR, Messing RO, Scheuer T, Catterall WA (2005) Specific modulation of $\mathrm{Na}^{+}$channels in hippocampal neurons by protein kinase C epsilon. J Neurosci 25:507-513. CrossRef Medline

Crespo C, Blasco-Ibáñez JM, Briñón JG, Alonso JR, Domínguez MI, Martínez-Guijarro FJ (2000) Subcellular localization of m2 muscarinic receptors in GABAergic interneurons of the olfactory bulb. Eur J Neurosci 12:3963-3974. CrossRef Medline

Dani JA, Bertrand D (2007) Nicotinic acetylcholine receptors and nicotinic cholinergic mechanisms of the central nervous system. Annu Rev Pharmacol Toxicol 47:699-729. CrossRef Medline

De Rosa E, Hasselmo ME, Baxter MG (2001) Contribution of the cholinergic basal forebrain to proactive interference from stored odor memories during associative learning in rats. Behav Neurosci 115:314-327. CrossRef Medline

de Olmos J, Hardy H, Heimer L (1978) The afferent connections of the main and the accessory olfactory bulb formations in the rat: an experimental HRP-study. J Comp Neurol 181:213-244. CrossRef Medline

Doty RL, Bagla R, Kim N (1999) Physostigmine enhances performance on an odor mixture discrimination test. Physiol Behav 65:801-804. Medline

D'Souza RD, Vijayaraghavan S (2012) Nicotinic receptor-mediated filtering of mitral cell responses to olfactory nerve inputs involves the $\alpha 3 \beta 4$ subtype. J Neurosci 32:3261-3266. CrossRef Medline

D'Souza RD, Parsa PV, Vijayaraghavan S (2013) Nicotinic receptors modulate olfactory bulb external tufted cells via an excitation-dependent inhibitory mechanism. J Neurophysiol 110:1544-1553. CrossRef Medline

Elaagouby A, Ravel N, Gervais R (1991) Cholinergic modulation of excitability in the rat olfactory bulb: effect of local application of cholinergic agents on evoked field potentials. Neuroscience 45:653-662. CrossRef Medline

Eyre MD, Antal M, Nusser Z (2008) Distinct deep short-axon cell subtypes of the main olfactory bulb provide novel intrabulbar and extrabulbar GABAergic connections. J Neurosci 28:8217-8229. CrossRef Medline

Fletcher ML, Chen WR (2010) Neural correlates of olfactory learning: critical role of centrifugal neuromodulation. Learn Mem 17:561-570. CrossRef Medline

Fletcher ML, Wilson DA (2002) Experience modifies olfactory acuity: acetylcholine-dependent learning decreases behavioral generalization between similar odorants. J Neurosci 22:RC201. Medline

Ghatpande AS, Gelperin A (2009) Presynaptic muscarinic receptors enhance glutamate release at the mitral/tufted to granule cell dendrodendritic synapse in the rat main olfactory bulb. J Neurophysiol 101:2052-2061. CrossRef Medline

Ghatpande AS, Sivaraaman K, Vijayaraghavan S (2006) Store calcium mediates cholinergic effects on mIPSCs in the rat main olfactory bulb. J Neurophysiol 95:1345-1355. CrossRef Medline

Giniatullin R, Nistri A, Yakel JL (2005) Desensitization of nicotinic ACh receptors: shaping cholinergic signaling. Trends Neurosci 28:371-378. CrossRef Medline
Gire DH, Franks KM, Zak JD, Tanaka KF, Whitesell JD, Mulligan AA, Hen R, Schoppa NE (2012) Mitral cells in the olfactory bulb are mainly excited through a multistep signaling path. J Neurosci 32:2964-2975. CrossRef Medline

Hayar A, Karnup S, Ennis M, Shipley MT (2004a) External tufted cells: a major excitatory element that coordinates glomerular activity. J Neurosci 24:6676-6685. CrossRef Medline

Hayar A, Karnup S, Shipley MT, Ennis M (2004b) Olfactory bulb glomeruli: external tufted cells intrinsically burst at theta frequency and are entrained by patterned olfactory input. J Neurosci 24:1190-1199. CrossRef Medline

Inokuchi A, Restrepo JP, Snow JB Jr (1987) Effect of stimulation of the horizontal limb of the diagonal band on rat olfactory bulb neuronal activity. Am J Otolaryngol 8:205-210. CrossRef Medline

Isaacson JS, Strowbridge BW (1998) Olfactory reciprocal synapses: dendritic signaling in the CNS. Neuron 20:749-761. CrossRef Medline

Isokawa M (1996) Decrement of GABAA receptor-mediated inhibitory postsynaptic currents in dentate granule cells in epileptic hippocampus. J Neurophysiol 75:1901-1908. Medline

Kasa P, Hlavati I, Dobo E, Wolff A, Joo F, Wolff JR (1995) Synaptic and non-synaptic cholinergic innervation of the various types of neurons in the main olfactory bulb of adult rat: immunocytochemistry of choline acetyltransferase. Neuroscience 67:667-677. CrossRef Medline

Kasowski HJ, Kim H, Greer CA (1999) Compartmental organization of the olfactory bulb glomerulus. J Comp Neurol 407:261-274. CrossRef Medline

Kiyokage E, Pan YZ, Shao Z, Kobayashi K, Szabo G, Yanagawa Y, Obata K, Okano H, Toida K, Puche AC, Shipley MT (2010) Molecular identity of periglomerular and short axon cells. J Neurosci 30:1185-1196. CrossRef Medline

Kosaka K, Kosaka T (2005a) synaptic organization of the glomerulus in the main olfactory bulb: compartments of the glomerulus and heterogeneity of the periglomerular cells. Anat Sci Int 80:80-90. CrossRef Medline

Kosaka T, Kosaka K (2005b) Structural organization of the glomerulus in the main olfactory bulb. Chem Senses 30 [Suppl 1]:i107-i108. CrossRef Medline

Kosaka T, Kosaka K (2011) "Interneurons" in the olfactory bulb revisited. Neurosci Res 69:93-99. CrossRef Medline

Kunze WA, Shafton AD, Kemm RE, McKenzie JS (1991) Effect of stimulating the nucleus of the horizontal limb of the diagonal band on single unit activity in the olfactory bulb. Neuroscience 40:21-27. CrossRef Medline

Lee MG, Hassani OK, Alonso A, Jones BE (2005) Cholinergic basal forebrain neurons burst with theta during waking and paradoxical sleep. J Neurosci 25:4365-4369. CrossRef Medline

Le Jeune H, Aubert I, Jourdan F, Quirion R (1995) Comparative laminar distribution of various autoradiographic cholinergic markers in adult rat main olfactory bulb. J Chem Neuroanat 9:99-112. CrossRef Medline

Linster C, Garcia PA, Hasselmo ME, Baxter MG (2001) Selective loss of cholinergic neurons projecting to the olfactory system increases perceptual generalization between similar, but not dissimilar, odorants. Behav Neurosci 115:826-833. CrossRef Medline

Liu S, Shipley MT (2008a) Intrinsic conductances actively shape excitatory and inhibitory postsynaptic responses in olfactory bulb external tufted cells. J Neurosci 28:10311-10322. CrossRef Medline

Liu S, Shipley MT (2008b) Multiple conductances cooperatively regulate spontaneous bursting in mouse olfactory bulb external tufted cells. J Neurosci 28:1625-1639. CrossRef Medline

Liu S, Plachez C, Shao Z, Puche A, Shipley MT (2013) Olfactory bulb short axon cell release of GABA and dopamine produces a temporally biphasic inhibition-excitation response in external tufted cells. J Neurosci 33: 2916-2926. CrossRef Medline

López-Bendito G, Sturgess K, Erdélyi F, Szabó G, Molnár Z, Paulsen O (2004) Preferential origin and layer destination of GAD65-GFP cortical interneurons. Cereb Cortex 14:1122-1133. CrossRef Medline

Ma M, Luo M (2012) Optogenetic activation of basal forebrain cholinergic neurons modulates neuronal excitability and sensory responses in the main olfactory bulb. J Neurosci 32:10105-10116. CrossRef Medline

Macrides F, Schneider SP (1982) Laminar organization of mitral and tufted cells in the main olfactory bulb of the adult hamster. J Comp Neurol 208:419-430. CrossRef Medline

Macrides F, Davis BJ, Youngs WM, Nadi NS, Margolis FL (1981) Cholinergic and catecholaminergic afferents to the olfactory bulb in the hamster: 
a neuroanatomical, biochemical, and histochemical investigation. J Comp Neurol 203:495-514. CrossRef Medline

Mandairon N, Ferretti CJ, Stack CM, Rubin DB, Cleland TA, Linster C (2006) Cholinergic modulation in the olfactory bulb influences spontaneous olfactory discrimination in adult rats. Eur J Neurosci 24:32343244. CrossRef Medline

Markopoulos F, Rokni D, Gire DH, Murthy VN (2012) Functional properties of cortical feedback projections to the olfactory bulb. Neuron 76: 1175-1188. CrossRef Medline

Matsushita N, Okada H, Yasoshima Y, Takahashi K, Kiuchi K, Kobayashi K (2002) Dynamics of tyrosine hydroxylase promoter activity during midbrain dopaminergic neuron development. J Neurochem 82:295-304. CrossRef Medline

McGann JP, Pírez N, Gainey MA, Muratore C, Elias AS, Wachowiak M (2005) Odorant representations are modulated by intra- but not interglomerular presynaptic inhibition of olfactory sensory neurons. Neuron 48:1039-1053. CrossRef Medline

Murphy GJ, Darcy DP, Isaacson JS (2005) Intraglomerular inhibition: signaling mechanisms of an olfactory microcircuit. Nat Neurosci 8:354-364. CrossRef Medline

Nickell WT, Shipley MT (1988a) Two anatomically specific classes of candidate cholinoceptive neurons in the rat olfactory bulb. J Neurosci 8:4482-4491. Medline

Nickell WT, Shipley MT (1988b) Neurophysiology of magnocellular forebrain inputs to the olfactory bulb in the rat: frequency potentiation of field potentials and inhibition of output neurons. J Neurosci 8:44924502. Medline

Nunez-Parra A, Maurer RK, Krahe K, Smith RS, Araneda RC (2013) Disruption of centrifugal inhibition to olfactory bulb granule cells impairs olfactory discrimination. Proc Natl Acad Sci U S A 110:14777-14782. CrossRef Medline

Oldenburg IA, Ding JB (2011) Cholinergic modulation of synaptic integration and dendritic excitability in the striatum. Curr Opin Neurobiol 21: 425-432. CrossRef Medline

Parrish-Aungst S, Shipley MT, Erdelyi F, Szabo G, and Puche AC (2007) Quantitative analysis of neuronal diversity in the mouse olfactory bulb. J Comp Neurol 501:825-836. CrossRef Medline

Pignatelli A, Belluzzi O (2008) Cholinergic modulation of dopaminergic neurons in the mouse olfactory bulb. Chem Senses 33:331-338. CrossRef Medline

Pinching AJ, Powell TP (1971a) The neuron types of the glomerular layer of the olfactory bulb. J Cell Sci 9:305-345. Medline

Pinching AJ, Powell TP (1971b) The neuropil of the glomeruli of the olfactory bulb. J Cell Sci 9:347-377. Medline

Pinching AJ, Powell TP (1971c) The neuropil of the periglomerular region of the olfactory bulb. J Cell Sci 9:379-409. Medline

Pírez N, Wachowiak M (2008) In vivo modulation of sensory input to the olfactory bulb by tonic and activity-dependent presynaptic inhibition of receptor neurons. J Neurosci 28:6360-6371. CrossRef Medline

Pressler RT, Inoue T, Strowbridge BW (2007) Muscarinic receptor activation modulates granule cell excitability and potentiates inhibition onto mitral cells in the rat olfactory bulb. J Neurosci 27:10969-10981. CrossRef Medline

Price JL, Powell TP (1970) An experimental study of the origin and the course of the centrifugal fibres to the olfactory bulb in the rat. J Anat 107:215-237. Medline

Quick MW, Lester RA (2002) Desensitization of neuronal nicotinic receptors. J Neurobiol 53:457-478. CrossRef Medline

Ramón y Cajal S (1911) Histologie du systeme nerveux de l'homme et des vertebres. Paris: Hachette.
Ravel N, Elaagouby A, Gervais R (1994) Scopolamine injection into the olfactory bulb impairs short-term olfactory memory in rats. Behav Neurosci 108:317-324. CrossRef Medline

Roman FS, Simonetto I, Soumireu-Mourat B (1993) Learning and memory of odor-reward association: selective impairment following horizontal diagonal band lesions. Behav Neurosci 107:72-81. CrossRef Medline

Rothermel M, Carey RM, Puche A, Shipley MT, Wachowiak M (2014) Cholinergic inputs from basal forebrain add an excitatory bias to odor coding in the olfactory bulb. J Neurosci 34:4654-4664. CrossRef Medline

Senut MC, Menetrey D, Lamour Y (1989) Cholinergic and peptidergic projections from the medial septum and the nucleus of the diagonal band of Broca to dorsal hippocampus, cingulate cortex and olfactory bulb: a combined wheatgerm agglutinin-apohorseradish peroxidase-gold immunohistochemical study. Neuroscience 30:385-403. CrossRef Medline

Shao Z, Puche AC, Kiyokage E, Szabo G, Shipley MT (2009) Two GABAergic intraglomerular circuits differentially regulate tonic and phasic presynaptic inhibition of olfactory nerve terminals. J Neurophysiol 101: 1988-2001. CrossRef Medline

Shao Z, Puche AC, Liu S, Shipley MT (2012) Intraglomerular inhibition shapes the strength and temporal structure of glomerular output. J Neurophysiol 108:782-793. CrossRef Medline

Shipley MT, Adamek GD (1984) The connections of the mouse olfactory bulb: a study using orthograde and retrograde transport of wheat germ agglutinin conjugated to horseradish peroxidase. Brain Res Bull 12:669688. CrossRef Medline

Tai C, Kuzmiski JB, MacVicar BA (2006) Muscarinic enhancement of R-type calcium currents in hippocampal CA1 pyramidal neurons. J Neurosci 26:6249-6258. CrossRef Medline

Takahashi Y, Kaba H (2010) Muscarinic receptor type 1 (M1) stimulation, probably through $\mathrm{KCNQ} / \mathrm{Kv} 7$ channel closure, increases spontaneous GABA release at the dendrodendritic synapse in the mouse accessory olfactory bulb. Brain Res 1339:26-40. CrossRef Medline

Thiele A (2013) Muscarinic signaling in the brain. Annu Rev Neurosci 36: 271-294. CrossRef Medline

Vucinic D, Cohen LB, Kosmidis EK (2006) Interglomerular centersurround inhibition shapes odorant-evoked input to the mouse olfactory bulb in vivo. J Neurophysiol 95:1881-1887. CrossRef Medline

Wachowiak M, McGann JP, Heyward PM, Shao Z, Puche AC, Shipley MT (2005) Inhibition [corrected] of olfactory receptor neuron input to olfactory bulb glomeruli mediated by suppression of presynaptic calcium influx. J Neurophysiol 94:2700-2712. CrossRef Medline

Wenk H, Meyer U, Bigl V (1977) Centrifugal cholinergic connections in the olfactory system of rats. Neuroscience 2:797-800. CrossRef Medline

White EL (1973) Synaptic organization of the mammalian olfactory glomerulus: new findings including an intraspecific variation. Brain Res 60: 299-313. CrossRef Medline

Woolf NJ, Eckenstein F, Butcher LL (1984) Cholinergic systems in the rat brain: I. Projections to the limbic telencephalon. Brain Res Bull 13:751784. CrossRef Medline

Zaborszky L, Carlsen J, Brashear HR, Heimer L (1986) Cholinergic and GABAergic afferents to the olfactory bulb in the rat with special emphasis on the projection neurons in the nucleus of the horizontal limb of the diagonal band. J Comp Neurol 243:488-509. CrossRef Medline

Zaborszky L, von den Pol A, Gyengesi E (2012) The basal forebrain cholinergic projection system in mice. In: The mouse nervous system (Watson C, Paxinos G, Puelles L, eds), pp 684-718. Amsterdam: Elsevier.

Zhan X, Yin P, Heinbockel T (2013) The basal forebrain modulates spontaneous activity of principal cells in the main olfactory bulb of anesthetized mice. Front Neural Circuits 7:148. CrossRef Medline 